\title{
MAGIC BULLET: THE HISTORY OF ORAL REHYDRATION THERAPY
}

\author{
by
}

JOSHUA NALIBOW RUXIN *

In February 1994, the directors of major United Nations agencies, the Prime Minister of Bangladesh, medical researchers, international health advocates and politicians gathered in Dacca, Bangladesh, to celebrate the twenty-fifth anniversary of a life-saving technique known as oral rehydration therapy (ORT). UNICEF and the International Centre for Diarrhoeal Disease Research organized the meeting in order to recognize those who originally developed and promoted the therapy and to refocus attention on the continued underutilization of ORT throughout the world.'

More than two decades earlier, in Dacca, East Pakistan, and Calcutta, India, many of the people who attended the meeting, along with others, had developed the use of an extraordinarily simple solution consisting of sugar, salts, and water to save the lives of severely dehydrated adults, children, and infants. ${ }^{2}$ These researchers, some of whom had not yet completed their medical residencies, were affiliated with powerful U.S. institutions including Johns Hopkins, Harvard, the Centers for Disease Control, the U.S. Navy, and the National Institutes for Health. In 1962 they began work on effective therapies for cholera-induced diarrhoea which was claiming thousands of lives globally during seasonal epidemics. Within six years, these men produced and synthesized physiological evidence that overturned the medical establishment's paradigm for diarrhoeal treatment. Through determination, intuition, and serendipity, they developed a new therapy which proved effective in clinical trials. Before its promotion worldwide in the late 1970 s, the majority of people with diarrhoeal dehydration had no access to effective treatment. ORT can be

\footnotetext{
* Joshua Nalibow Ruxin, MPH, Wellcome Institute for the History of Medicine, 183 Euston Road, London NWI 2BE.

I am grateful to the following for their constructive commentary on earlier versions of this essay-Fred Strebeigh, R. Bradley Sack, Dilip Mahalanabis, three anonymous referees, and Prof. W. F. Bynum. I am especially thankful to my original essay advisor at Yale, Professor Mark Micale, for his unswerving encouragement and sage criticism. David R. Nalin and Nathaniel F. Pierce provided me with exceptional historical and scientific insights throughout the course of writing this paper. Lastly, I am deeply indebted to Bucky Greenough, Richard Cash, Bert Hirschhorn and the other interviewees whose concise views and colourful anecdotes enhanced this essay. My initial interest in writing a history of oral rehydration therapy was sparked and advanced by opportunities made available by the Yale Class of 1960) and Bates travel fellowships, Demissie Habte at the International Centre for Diarrhoeal Disease Research, Bangladesh, the Harry S. Truman Foundation and Save the Children.

' Demissie Habte, personal communication, March 1994.

2 Dacca, East Pakistan, became known as Dhaka, Bangladesh, after the establishment of the People's Republic of Bangladesh in 1971, for simplicity`s sake the former spelling is used throughout.
} 


\section{Joshua Nalibow Ruxin}

utilized effectively in even the most isolated parts of the world and today saves the lives of over one million children annually. ${ }^{3}$

Every year, in every developing country, diarrhoea has been one of the leading causes of childhood death. ${ }^{4}$ Since ORT requires only sugar, salts, and water mixed in proper proportions, it might be expected that some person would have discovered it - or at least a crude equivalent-long ago. However, although some cultures and societies developed oral therapies believed to be effective, no one remedy ever gained global acceptance. Rather, most cultures developed local therapies ranging from coconut milk to emetics.

The simplicity of ORT contrasts starkly with the story of its discovery which overflows with abrasive personalities, professional jealousies, and scientific breakthroughs, as well as with an unusual degree of scientific co-operation. An analysis of the pertinent scientific papers alone fails to convey adequately the story of ORT and suggests that its development was a smooth, linear progression of innovations. However, in the eyes of many of its greatest advocates and contributors, the development itself constitutes a scientific revolution. The history of ORT reveals an extraordinarily long path to discovery followed by an ongoing struggle for legitimacy and implementation. When examined in historical context, the account lends itself to discussion of many of the themes which perplex medical historians: the conflicts between "high" and "low" technology, between laboratory and clinical science, and between public health and medical research. Furthermore, it demonstrates how the prejudices of the medical establishment and its reverence for advanced technology can postpone life-saving discoveries.

Despite the significance of ORT, the story of its discovery, like other twentieth-century public health accomplishments, has remained largely untold. ${ }^{5} \mathrm{~A}$ few of the researchers involved have written their accounts in short articles for specialized conferences on ORT and scientific journals. These publications, however, fall short of defining the context in which the discovery was made and fail to cover all the events associated with it. The only book that extensively addresses the subject, Cholera: the American scientific experience 1947-1980, written by W. E. van Heyningen and John R. Seal, lacks historical analysis, focuses on cholera, and contains numerous factual errors. ${ }^{6}$ Moreover, the views presented are coloured by Seal's involvement with ORT, thereby producing a biased presentation. Fortunately, most of the researchers involved in the development of ORT remain alive and active today. This narrative relies on a series of personal interviews and correspondence

\footnotetext{
${ }^{3}$ Norbert Hirschhorn and William B. Greenough III, 'Progress in oral rehydration therapy', Scientific American, 1991, 264 (5): 50-6. See also, UNICEF, The state of the world's children 1994, Oxford University Press, 1993, p. 6.

${ }^{4}$ UNICEF, op. cit., note 3 above, p. 6.

${ }^{5}$ Another recent public health achievement that ranks with oral rehydration therapy was the global eradication of smallpox, officially completed in 1979. In an earlier paper I investigated the media's coverage of the smallpox eradication campaign and found that it was largely overlooked by popular journals, newspapers and medical publications. Apparently, journalists do not think scientific ventures that utilize relatively basic technology deserve an audience.

${ }^{6}$ W. E. van Heyningen and John R. Seal, Cholera: the American scientific experience, 1947-1980, Boulder, Colorado, Westview Press, 1983. This book is largely based on the opinions of Seal, who directed NIH's Cholera Technical Advisory Committee. A few of the central problems of van Heyningen's and Seal's text are described in the footnotes of this paper. Van Heyningen's correspondence from 1967-78 relating to his work on cholera and as consultant to the Pakistan-SEATO Cholera Research Laboratory in Dacca, is held at the Contemporary Medical Archives Centre (CMAC) at the Wellcome Institute for the History of Medicine, London.
} 


\section{The history of oral rehydration therapy}

with more than a dozen of the most significant figures. The majority of their insights, perceptions, and anecdotes are previously undocumented. Based on these interviews and scientific publications, this paper first establishes a framework for understanding the state of diarrhoeal physiology and therapy before work in Dacca and Calcutta began in 1962. It then turns specifically to Dacca and traces the developmental research preceding the execution of the first clinical trial of a practical oral therapy in 1968. Next, it briefly follows the spread of the therapy's use from Dacca and Calcutta to the rest of the developing world, before turning finally to examine the uneven path to the acceptance of oral therapy.

\section{DIARRHOEA: THE GLOBAL KILLER}

During the late 1970 s world health experts estimated that the approximately 500 million annual episodes of diarrhoea in children under the age of five resulted in at least five million deaths per year. ${ }^{7}$ These generally occurred in the developing world where one in ten children died of diarrhoea before the age of five. ${ }^{8}$ Although these statistics are recent, the tragedy they reflect is not exclusively a modern phenomenon. Sanskrit literature and the Hippocratic corpus contain discussions about the scourge of diarrhoea and its treatment. ${ }^{9}$ While healers continued to discuss diarrhoea during the following centuries, they made little progress toward understanding its causes or developing a widely available treatment.

Diarrhoea is not a disease; it is a symptom whose aetiology includes food poisoning, bacterial and other microbial infections, and it can be deadly. The dehydration it causes can quickly destroy the ability of a body to function. Children under the age of five are especially susceptible to diarrhoea, and in severe cases their mortality rate often exceeds 50 per cent. The condition is most harmful to young children since they daily exchange more than one half of their extracellular fluid in the gut compared to one seventh exchanged by adults. ${ }^{10}$ If this fluid exchange is impaired, a child becomes dehydrated much more quickly than an adult. When diarrhoea strikes a child, the body begins to expel essential electrolytes and water. This depletion may quickly lead to dehydration. The characteristics of choleraic dehydration, which differ little from the dehydration of other aetiologies, are well known to doctors in the developing world. According to one physician the dehydration manifests itself in the following manner,

The eyes and the cheeks are sunken, the face is pinched, the lips and the tongue are dry, the fingertips are shriveled ("washerwoman's hands"), and the voice is hoarse ... If the skin is pinched, especially over the abdomen, the skin folds do not disappear for some time ... The pulse pressure decreases and it becomes imperceptible on the radial arteries ... The

7 'Control of diarrhoeal diseases: WHO's programme takes shape', WHO Chronicle, 1978, 32 (10): 369-72, on p. 369.

${ }^{x}$ Robert L. Parker, Ward Rinehart, Phyllis T. Piotrow, and Louise Doucette, 'Oral rehydration therapy (ORT) for childhood diarrhea', Population Reports, January 1985, 12 (4): p. L-41.

"Susruta, an ancient Indian medical figure and the father of Ayurvedic medicine (c. $1500 \mathrm{BCE})$, prescribed that diarrhoea victims should be "given to drink a profuse quantity of tepid water in which rock salt and molasses have been dissolved; or clarified water combined with rice gruel”, Susruta Samhita III, verse II. See also, Dr William B. Greenough III, interview, 5 February 1992, transcript p. 8, and Harris L. Smith MD, 'Historical notes on parenteral fluid therapy of diarrhea in infants', $J$ Pediatr., October 1960, 57 (4): 611-16, on p. 611.

1" Leroy J. Stephens, MD, and William E. Henrickson, 'Mild diarrhea in children', Mo. Med.-J. Missouri State Med. Ass., 1954, 51 (2): pp. 105-6. 


\section{Joshua Nalibow Ruxin}

urine diminishes in quantity ... Muscle cramps, principally of the extremities but also of the trunk, are common at this stage ... In fatal instances, death often ensues on the second or third day of the disease ...11

The sight and plight of patients in this condition encouraged researchers to find better ways of treating diarrhoeal dehydration, but despite extensive experimentation, it was not until the mid 1920s that a relatively effective and safe treatment emerged. This entailed rehydration with expensive hospital-administered intravenous solutions. Although efficacious, it was essentially unavailable to the people most plagued by diarrhoea, those in the developing world.

The prevalence of cholera in the developing world inspired many scientists to search for a therapy that could be utilized in the field, far away from hospitals and the technologically advanced intravenous treatment. William B. Greenough III, a physician who was intimately involved with the study of cholera and worked for several years in Dacca, has pointed out that intravenous treatment was totally inadequate for cholera cases in the field: "I've been in the field with five thousand cases of cholera when the only thing you could do was ... drag people who were infected into the middle of the field so that they would not infect everyone else. So it was obvious that without some breakthrough . . . you were not going to make a dent in cholera." 12

\section{THE SEARCH FOR AN EFFECTIVE TREATMENT}

In western medicine most scientific research on diarrhoea during the first half of the twentieth century can be divided into two categories. There were those researchers who studied the various aetiologies of diarrhoea and conceived of antibiotic treatments as a cure. They often subordinated practical issues of dehydration treatment and concentrated their efforts on the pathogen because they believed that the most effective therapies for diarrhoeal diseases could be found only when the causes were known. ${ }^{13}$ Other researchers concentrated on finding a solution that could consistently rehydrate children without complications. Some of these people favoured various isotonic electrolyte solutions for diarrhoeal treatment. This categorization, however, should not suggest that there were two separate groups; in fact, many researchers concerned themselves with all aspects of diarrhoeal disease.

Those who searched for a universal cure for diarrhoea often advocated solutions concocted from carob flour, bananas, or other substances. In 1950, Per Selander, a Swedish doctor, championed the use of carrot soup at a time when some American doctors were publicizing the attributes of carob flour and dehydrated bananas. ${ }^{14}$ According to Selander, "Carrot soup is an extremely reliable, easily obtainable, and simple, nourishing substance

\footnotetext{
11 Oscar Felsenfeld, The cholera problem, St Louis, Missouri, Warren H. Green, Inc., 1967, pp. 59-60.

12 William B. Greenough III, interview, 5 February 1992, transcript p. 3.

${ }^{13}$ Milton Feig, 'Diarrhea, dysentery, food poisoning, and gastroenteritis', Am. J. Publ. Health, November 1950, 40 (11): 1372-94.

14 Joseph H. Fries, Nicholas J. Chiara, and Robert J. Waldron, 'Dehydrated banana in the dietetic management of diarrheas of infancy', J. Pediatr., 1950, 37 (3): 367-72, on p. 367. See also Alan E. Smith and Carl C. Fischer, 'The use of carob flour in the treatment of diarrhea in infants and children', J. Pediatr., 1949, 35 (5): $422-6$, on p. 422. William Z. Fradkin, 'The dietary treatment of diarrheal diseases', Am. J. Digestive Disorders, July 1953 , pp. 208-10.
} 


\section{The history of oral rehydration therapy}

which acts promptly in the treatment of acute diarrhoeal disturbances in infants. In my own experience, I have found carrot soup to be far superior to all substances hitherto employed." 15 Regardless of effectiveness, diarrhoeal treatments like Selander's reflected the lack of information doctors then had about the physiological mechanisms of diarrhoea. The developers of these treatments therefore gauged their success on a case-by-case basis: how many patients improved and how quickly. They did not explain why they improved.

Nevertheless, these eccentric therapies often produced outwardly impressive results while utilizing methodologies now considered archaic. In a 1950 study that used dehydrated banana, the average time of complete recovery from dehydration in infants who received the treatment was 2.9 days, in sharp contrast to 5.02 days for the control group receiving routine hospital therapy. ${ }^{16}$ Fruit and vegetable therapies were always oral, whereas most others remained intravenous. Doctors found that intravenous solutions worked well and provided them with precise control over the treatment, while oral solutions appeared scientifically unsound.

The composition of intravenous solutions changed with increased metabolic research during the 1940s and 1950s, yet, despite this, the basic treatment protocol remained the same. The therapy involved the parenteral administration of electrolyte solutions, blood transfusions, fasting, and the gradual commencement of feeding at the end of the "starvation" period. ${ }^{17}$ This fasting was a crucial element of most diarrhoeal therapies and was based on the pervasive beliefs that the gastrointestinal tract required an opportunity to rest and recover and that oral intake aggravated diarrhoea since the diarrhoeic gut could not absorb fluids. ${ }^{18}$ With therapies of this sort, infants often needed to stay in hospital for one to two weeks in order to recover. ${ }^{19}$ These lengthy stays can partly be attributed to the malnourishing effect of the treatments on the patients. Even with these therapies, public health physicians worried about infant diarrhoeal epidemics in nurseries which "frequently develop[ed] a high case fatality rate with attendant unfavorable publicity". ${ }^{20}$ These high death rates highlight the overall ineffectiveness of the treatments then available; diarrhoea still posed a major public health threat to young children.

\section{DANIEL DARROW AND THE COMPOSITION OF DIARRHOEA}

At the heart of ineffective diarrhoeal therapies was a lack of knowledge about the electrolytes expelled and how best to replenish them. During the 1940s Dr Daniel Darrow of Yale University began ground-breaking electrolyte studies that reverberated through the scientific community; at the same time much work was being done on the physical processes in the body that diarrhoea interrupts and alters. ${ }^{21}$ Darrow began advocating rehydration solutions that included potassium, sodium chloride, and glucose based on

\footnotetext{
15 Per Selander, 'Carrot soup in the treatment of infantile diarrhea', J. Pediatr., 1950, 36 (6): 742-5, on p. 743.

16 Fries, Chiara, and Waldron, op. cit., note 14 above.

${ }^{17}$ Harold E. Harrison, 'The treatment of diarrhea in infancy', Pediatr. Clin. North Am., Symposium on Clinical Advances, May 1954, pp. 335-48, on p. 338. Parenteral treatment refers to any solution that is injected into the body. Most commonly it indicates an intravenous (IV) injection.

${ }^{18}$ Carl A. Holmes, 'Diarrhea with dehydration in infants", Arizona Medicine, 1955, 12 (5): 195-6, on p. 196.

19) Ibid., p. 195.

20) D. Crosby Greene and Robert M. Albrècht, 'Recent developments in diarrhea of the newborn', NY State J. Med., 1955, 55 (1): 2764-8, on p. 2764.

${ }^{2}$ Smith, op. cit., note 9 above, p. 614 .
} 


\section{Joshua Nalibow Ruxin}

sound physiological observations and principles. ${ }^{22}$ The opening statement in his significant 1949 article well reflects his focus: "Effective replacement of water and electrolyte in patients with diarrhoea should be based on exact knowledge of changes in composition of body fluids." ${ }^{23}$ He believed that one could not blindly treat diarrhoeal dehydration without understanding what the body was losing. Consequently, his studies described which electrolytes are lost in an episode of diarrhoea and in what quantities they should be introduced back into the body. Although he did not champion an oral therapy over parenteral treatment, he concluded that an oral solution of potassium, lactate, and glucose could help restore lost water and electrolytes and thereby avoid "prolonged parenteral therapy". ${ }^{24}$ Darrow's intravenous and oral treatment brought the case fatality rate of babies with moderate to severe dehydration below 5 per cent. ${ }^{25}$ Eighteen years later this method of limited parenteral therapy followed by an oral electrolyte and glucose solution, with some refinements and a new physiological paradigm, would be known as oral rehydration therapy. Darrow laid the foundation for future research by recognizing that treatment, at least in the clinical stages, could not consist of a guessing game to ascertain which vegetable formula or solution worked best.

Scientists involved in the discovery of ORT disagree on the importance of his contribution. Greenough believes that Darrow developed good rational therapeutic solutions, especially one which could be parenterally administered. Although it was important that Darrow drew scientific attention to the repair of electrolyte deficits in children, Greenough asserts that "he did not have any of the information which allowed them [oral solutions] to take off after 1967 or $1968 " .{ }^{26}$ Dr Norbert Hirschhorn, who played a major role in the development of ORT, agrees with Greenough, but gives more credit to Darrow for having pinpointed which electrolytes needed replenishing. Hirschhorn points out that before Darrow, rehydration solutions "had been quite empiric-sometimes they threw a lot of salt in, sometimes a lot of bicarbonate or lactate in it". ${ }^{27}$ In all rehydration therapies there was inadequate correlation between what the body lost and what doctors reintroduced into the patient.

Darrow's work seemed all the more significant since children were particularly at risk from debilitating or fatal dehydration due to the lack of physiological knowledge and its reflection in various products. For example, infant formulas and over-the-counter oral rehydration solutions contained far too much sugar and salt, a potentially lethal combination which aggravated diarrhoea. ${ }^{28}$ When a person ingests a solution with a higher concentration of sugar or salt than the body, water osmotically leaves the body and enters the intestinal lumen (in an attempt to maintain isotonicity), and this results in dehydration as well as higher salt concentrations in the body. ${ }^{29}$ Concentrated sugar and salt solutions employed in the 1950s were born of a lack of knowledge of certain biological mechanisms

22 Daniel Darrow, et al., 'Disturbances of water and electrolytes in infantile diarrhea', J. Pediatr., 1949, 3: 129-56.

${ }^{23}$ Ibid., p. 129.

24 Ibid., p. 151.

25 Ibid., p. 152.

${ }^{26}$ Greenough, interview, 5 February 1992, transcript p. 8.

${ }^{27}$ Dr Norbert Hirschhorn, interview, 10 January 1992, transcript p. 1.

${ }^{28}$ Greenough, interview, 10 January 1992, transcript p. 8.

${ }^{29}$ This clinical state is referred to as hypernatremia. 


\section{The history of oral rehydration therapy}

combined with recognition of the efficacy of some solutions. ${ }^{30}$ It is not surprising that the majority of physicians held fast to the parenteral route since only a few voices in the medical community affirmed that some oral electrolyte solutions, at least in mild cases of diarrhoea, were as efficacious as the intravenous route. ${ }^{31}$

Although Darrow may have produced some effective parenteral and oral therapies, his premise for oral rehydration highlights why his studies did not lead directly to modern day ORT. ${ }^{32} \mathrm{He}$ and other doctors at the time viewed oral treatments, at best, as an intermediate step between intravenous therapy and feeding. As Hirschhorn explains, oral rehydration for Darrow was not "a way of replacing intravenous fluids or a way of providing fluids to a population that would not have intravenous fluids". ${ }^{33}$ Unlike the Dacca and Calcutta investigators, Darrow was not exposed to the need for a simple oral solution.

\section{GLUCOSE, SODIUM, AND WATER TRANSPORT}

The practical applications of physiological findings in the 1950s remained limited to parenteral therapy and rarely, if ever, pointed toward an oral therapy. In 1953 R. B. Fisher and D. S. Parsons, sugar physiologists at the University of Oxford, discovered part of the mechanism for glucose transport across the excised small intestinal wall of the rat. Although scientists had previously assumed that many cells were permeable to glucose in the small intestine, Fisher and Parsons found that glucose appeared to be transported across the intestine by only a few cells; the others were impermeable to it. ${ }^{34}$ They therefore concluded that there might be specific receptor sites for glucose-a crucial component for the eventual understanding of rehydration therapy. However, researchers at the time did not recognize that, if glucose were to be a part of a rehydration solution, the function of these receptor sites should not be impaired.

There was no obvious link between Fisher's and Parsons' work and a rehydration solution. Fisher and Parsons were strictly physiologists: they made no mention of rehydration solutions and experimented only in vitro. Lacking evidence to the contrary, electrolyte physiologists believed that glucose absorption was paralysed during diarrhoea, and clinicians therefore advocated resting the bowel. The misconception, which seemed plausible at the time, was that any solution which entered the gastrointestinal track during diarrhoea, particularly choleraic diarrhoea, would be expelled.

The work of Fisher and Parsons furthered Darrow's research and inspired extensive studies of electrolyte transport in the intestinal tract. Their work was not immediately applied practically since past findings had not been replicable in vivo. Following in their footsteps, the physiologists Riklis and Quastel published the results of an important in vitro work on sugar absorption in 1958. They were the first to demonstrate that the active absorption of glucose in excised guinea pig intestine is dependent on the presence of sodium ions. They also began to find the concentrations for optimal water, sodium, and glucose

\footnotetext{
${ }^{30}$ Greenough, interview, 16 December 1991. See also, Eleanor Colle, et al., 'Hypertonic dehydration (hypernatremia): the role of feedings high in solutes', Pediatrics, 1958, 22(5): 55-12.

${ }^{31}$ Stephens and Henrickson, op. cit., note 10 above.

${ }^{32}$ See Daniel C. Darrow and John S. Welsh, 'Recent experience in the treatment of diarrhea in infants', $J$. Pediatr., 1960, 56 (2): 204-10.

${ }^{3.3}$ Hirschhorn, interview, 10 January 1992, transcript p. 1.

${ }^{34}$ R. B. Fisher and D. S. Parsons, 'Glucose movements across the wall of the rat small intestine', J. Physiol., 1953, 119: 210-23.
} 


\section{Joshua Nalibow Ruxin}

absorption. ${ }^{35}$ Riklis and Quastel inspired another sugar physiologist, Robert Crane, to define the mechanism for the active transport of glucose in the presence of sodium. ${ }^{36}$ All these studies ultimately helped in the understanding, if not the development, of ORT since they illustrated the coupling of glucose and sodium, the therapy's major constituents. This type of research would later be relevant when the effective and relatively safe concentrations of modern oral therapy were being determined. ${ }^{37}$

Most acute watery diarrhoeal diseases, such as cholera, do not destroy the mucosal membrane of the small intestine, although they may alter it. ${ }^{38}$ While diarrhoea results from an increase in the net fluid output from the intestine which in turn leads to dehydration, the absorption of fluid may continue-the problem lies with the net output. One could try to rehydrate by drinking lots of water, but would still lose water and expel much more salt. This is where ORT and the glucose and sodium chloride mechanism are relevant. When glucose is added to the mucosal membrane (where it is absorbed by the sites R. B. Fisher proposed), sodium chloride intake is greatly increased along with glucose and water. Even if the person continues to expel considerable amounts of fluid, the glucose allows the absorption of more fluid than is being expelled. Diarrhoea may continue, but the dehydration will be corrected. ${ }^{39}$

With the close of the 1950s, a new force in physiology emerged at the Harvard Biophysics laboratory. There, Drs Curran, Zalusky and Schultz furthered the work of earlier physiologists and concentrated on links between sugar and salt absorption. ${ }^{40} \mathrm{Dr}$ Michael Field, who worked in the laboratory during the time of Schultz, Curran, and Zalusky, contends that their work "showed two things: one is that sodium dependence of sugar absorption really means that sugar and sodium are absorbed together, that is that their movement is coupled on a particular transport protein ... and then they showed it also to be true for amino acids". ${ }^{41}$ It was the sugar and sodium co-transport mechanism which Schultz and Curran elegantly documented that was the cornerstone of their work. ${ }^{42}$

Schultz and Curran's work had broad implications for electrolyte physiologists. When Darrow put glucose in his rehydration solutions during the late 1940s, he did so in part because he thought that it contributed calories to the patient's system. Schultz and Curran demonstrated that the function of glucose in solution was "entirely independent of

\footnotetext{
${ }^{35}$ E. Riklis and J. H. Quastel, 'Effects of cations on sugar absorption by isolated surviving guinea pig intestine', Can. J. Biochem. Physiol., 1958, 36 (3): 347-62.

${ }^{36}$ Robert K. Crane, 'Hypothesis for mechanism of intestinal active transport of sugars', Federation Proceedings, November-December 1962, 21: 891-5. Dr Michael Field, interview, 19 February 1992, transcript p. 2. See also Dr Stanley G. Schultz, interview, 24 February 1992, transcript p. 4.

${ }_{37}$ Although oral therapy studies frequently cited Crane, they rarely, if ever, mentioned researchers such as Riklis and Quastel.

${ }^{38}$ Dr R. B. Sack, written comments, September 1993. Dilip Mahalanabis, interview and personal communications, August 1993. Also David Nalin, personal communication, April 1994. Dysenteries, for example, do damage the membrane.

${ }^{39}$ Richard Cash MD, 'A history of the development of ORT', Symposium Proceedings Cereal-Based Oral Rehydration Therapy: theory and practice, 17 February 1987, pp. 10-15.

(1) Dr Field, interview, 19 February 1992, transcript p. 2.

${ }^{41}$ Ibid. Field asserts that Schultz and Curran "were the centres of that [sugar and sodium physiology| work".

${ }^{42}$ Stanley G. Schultz, Robert E. Fuisz, and Peter F. Curran, 'Amino acid and sugar transport in rabbit ileum', J. Gen. Physiol., 1966, 49: 849-66. See also, Peter F. Curran, 'Sodium, chloride, and water transport by rat ileum in vitro', J. Gen. Physiol., 1960, 43: 1137-48.
} 
metabolic pathways" and was not to provide energy. ${ }^{43}$ Like the other physiological studies discussed, the findings of Schultz and Curran pertained to the normal physiology of the gut, they were not intended for application to diarrhoeal treatment.

By the 1960s, physiological knowledge of fluids reflected the dualistic approach of physiologists to their work. They recognized the inadequacies of their findings, while, at the same time, anticipating major breakthroughs. Perhaps the words of Dr Harris L. Smith best exemplify this: "Only the foundations," he wrote, "have been laid for our understanding of the basic physiology of cells and their environment. Undoubtedly a multitude of exciting discoveries awaits physicians, investigators, and practitioners alike, in the realm of body fluid dynamics and in their application to diagnosis and therapy."44 Months later, after rigorous comparisons of the available parenteral therapies, Smith's optimism plummeted, and he conceded that "the gaps in our understanding of the physiology of body fluid, both in health and in disease, have thus far precluded the formulation of a completely ideal regimen of parenteral fluid therapy for severe diarrhoea in infants". ${ }^{45}$ The decade began without a manageable oral therapy or a widely-practised effective parenteral therapy.

\section{CAPTAIN PHILLIPS' CHOLERA TREATMENT}

In September 1961, a cholera pandemic broke out in the Philippines. At that time, Dr Robert A. Phillips, whose cholera-related work dated back to 1947, sent a team from NAMRU-2 (Naval Medical Research Unit) in Taipei, Taiwan, to treat patients at San Lazaro hospital in Manila. Using Phillips' parenteral cholera treatment, which he had improved over the years, the hospital maintained a low mortality rate of 3.4 per cent. Lieutenant Commander Craig Wallace managed the operation of the treatment centre. ${ }^{46}$ When cholera returned in the summer of 1962, Phillips and his colleague Wallace picked up where some of Phillips' previous physiological studies had left off and began further experimentation on cholera patients. For two patients, Phillips added glucose to electrolyte solutions taken by mouth. ${ }^{47} \mathrm{He}$ was astounded to find that the addition tremendously enhanced sodium absorption-the same observation that several physiologists such as Crane, Schultz and Curran had already made in vitro using healthy animal gut. Unlike his predecessors, Phillips utilized a diarrhoeal model.

According to some researchers familiar with Phillips and his work, Phillips sought a solution that contained less sodium electrolyte but remained isosmolar; he wanted a non-electrolyte to replace some of the sodium in the solution and the non-electrolyte on the shelf was glucose. These researchers further assert that Phillips chose glucose only to maintain the molarity of the solution; his decision was independent of the physiological studies that had shown that it could augment absorption in non-diarrhoeal in vitro preparations. ${ }^{48}$ Had Phillips been guided by Schultz's and Curran's work, history might

${ }^{4.3}$ Hirschhorn, interview, 10 January 1992, transcript p. 2.

${ }^{44}$ Smith, op. cit., note 9 above, p. 614.

${ }^{45}$ Harris L. Smith and James N. Etteldorf, 'Parenteral fluid regimens in the treatment of severe diarrhea in infants', J. Pediatr., 1961, 58 (1): 1-16, on p. 14.

${ }^{46}$ Dr Craig K. Wallace, personal communication, April 1994.

${ }^{47}$ Van Heyningen and Seal, op. cit., note 6 above, pp. 72, 228-30.

${ }^{48}$ Dr David Nalin, interview, 14 February 1992, transcript p. 3. See also Cash, op. cit., note 39 above, p. 11. Cash claims that Phillips was unaware of the co-transport studies conducted by Riklis and Quastel, as well as those by 


\section{Joshua Nalibow Ruxin}

display a smooth and tidy scientific progression of discoveries from in vitro physiological observations to clinical application. ${ }^{49}$ The record on this point, however, is anything but neat.

Regardless of the influences, Phillips' work first demonstrated that oral therapy could be viable. Today, most ORT researchers praise Phillips for his finding. They believe that it was doubly important since it furthered studies carried out only in animal models, and it contradicted the conventional wisdom of the time which required that the gut be starved in all diarrhoeal treatment. Phillips had shown that cholera patients might be able to drink their therapy. This was the first discovery of a rational scientifically-based oral therapy for cholera patients.

Spurred on by this success, Phillips excitedly extrapolated his observation to a clinical trial. On 4 August 1962, his team in Manila, led by Wallace, treated three patients with a potent oral electrolyte solution containing high concentrations of glucose and sodium and achieved good results. Phillips then instructed Wallace to set up a large clinical trial for this solution, to be carried out in September when Phillips would be away. Of the thirty patients involved in the study, five died. ${ }^{50}$ Since the oral solutions were three times isotonic concentration, and intravenous fluids were co-administered, fluid overload resulted and this led to congestive heart failure. ${ }^{51}$

Their deaths may also have occurred because, as one researcher maintains, the clinical trial was carried out under conditions which were inferior to a standard trial since "Phillips wanted a method to approximate actual physical facilities then present in much of the world".52 Phillips did not prescribe standard patient monitoring because he wanted even a young child to be able to carry out the treatment. ${ }^{53}$ Given the nature of a potential panacea for diarrhoea, he recognized that it would have to be utilizable under terrible conditions; his experiment attempted to replicate these and confirm the treatment. Perhaps Phillips believed that he was on the verge of discovering a magic bullet for dehydration caused by cholera. Accordingly, he held a press conference before sending Wallace off to carry out the clinical trial. He reportedly stated that he and his colleagues were on the verge of discovering an oral cure for cholera. ${ }^{54}$ This public optimism probably made the failure immensely more painful. The experimental methodology Phillips used was

\footnotetext{
Schultz and Curran. See also van Heyningen and Seal, op. cit., note 6 above, pp. 229-30. Dr Graham Bull, who analysed the data with Phillips, agrees with Cash's assessment, while other physicians disagree with this perspective. Dr Charles C. J. Carpenter visited Phillips and Wallace soon after the experiment and asserts that the co-transport work of Schultz and Curran inspired Wallace and Phillips to introduce glucose into the solution. Dr Charles C. J. Carpenter, interview, 27 February 1992, transcript p. 2. Although Seal implies that Wallace would agree with Carpenter's view, today Wallace asserts that the choice of glucose was "more than serendipity ... lit was $\mid$ an educated guess". He states that the physiological work of Schultz, Curran and others did not provide the impetus. Rather, that glucose was one of a few non-electrolytes of choice in related physiological studies. Wallace, personal communication, April 1994.

${ }^{49}$ Nalin notes, however, that there was not truly a bridge between in vitro work (like that of Schultz and Curran) and in vivo work. These types of research were like "night and day" and a major leap of faith would have been needed to apply a principle demonstrated only in healthy excised animal tissue to a human diarrhoeal patient. Nalin, personal communication, 8 April 1992

5o) Wallace relates that, of the five who died, a few were conpromised patients already suffering from tuberculosis and other diseases. Wallace, personal communication, April 1994.

51 Van Heyningen and Seal, op. cit., note 6 above, pp. 231-3.

52 Cash, op. cit., note 48 above, p. 11.

${ }^{5.3}$ Remark by Craig Wallace in van Heyningen and Seal, op. cit., note 6 above, p. 232.

${ }^{54}$ Van Heyningen and Seal, op. cit., note 6 above, p. 231.
} 


\section{The history of oral rehydration therapy}

weakened not only by his search for a magic bullet, but also by a faulty scientific hypothesis. According to Hirschhorn, Phillips and his colleagues worked on the premise that the intestinal sodium pump had been poisoned by cholera. ${ }^{55}$ The purpose of the so-called "cholera cocktail" was therefore to "unpoison the pump". 56

The deaths that resulted had major repercussions for Phillips and his colleagues. According to a visitor at the Naval Research Center in the Philippines during the autumn of 1962, soon after the tragedy, Wallace "felt badly about it", and Phillips "felt so badly about it he didn't pursue it any further". ${ }^{57}$ These emotions even led Phillips to conceal the deaths and to delay publishing the other results, including his distinguished verification of glucose-sodium absorption in vivo, until 1964.

Phillips' 1964 paper explicitly cites the hypothesis of the poisoned sodium pump and, moreover, does not cite any of the sugar-sodium physiologists who had theorized glucose-sodium coupled transport. ${ }^{58}$ This void further demonstrates that Phillips was ostensibly uninspired by such physiological work and perhaps ignorant of it. His failure to mention the physiologists also suggests that their in vitro studies in non-diarrhoeal models were not the likely route to a diarrhoeal therapy given the attitudes of the day. ${ }^{59}$ Most significantly, Phillips reported that with glucose and sodium solutions (such as the ones he used in August 1962) the rate of sodium depletion decreased and glucose was absorbed, and he stated, for the first time, that the function of the glucose transport mechanism was apparently unimpaired in cholera. ${ }^{60}$ Some of the important observations Phillips presented could have been supported by current physiological research; had he correlated such work with his own, he might have been on the verge of discovering oral therapy. By the same token, he could not have carried out his fatal experiment since he would have recognized that no acceptable physiological hypothesis supported his concentrated solution. Moreover, had he promptly published his results, more progress on oral therapy might have been made by other investigators.

Clearly concerned with his failure, Phillips expressed extreme caution in the conclusion of the 1964 paper, writing that an oral regimen "can only be validated by careful balance studies". ${ }^{61}$ It was the lack of such studies during the experiments in the Philippines that resulted in the five deaths. Despite this tragedy, Phillips expressed cautious optimism for the future of oral solutions, "one may be able to develop an oral treatment regimen which in the average case might completely eliminate the requirement for intravenous fluids". 62

\$5 See R. A. Phillips, 'Water and electrolyte losses in cholera', Federation Proceedings, 1964, 23: 705-12.

${ }^{56}$ Hirschhorn, interview, 10 January 1992, transcript p. 3. Dr Henry Mosley, who later worked very closely with Phillips in Dacca, East Pakistan, alleges that Phillips' belief was that the oral rehydration cocktail "would reverse the fluid loss and that the patient would absorb their own water, so to speak, back into the intestine with the salt and sugar”. Mosley, interview, 25 February 1992, transcript p. 2.

${ }^{57}$ Carpenter, interview, 21 February 1992, transcript p. 1.

${ }^{58}$ Phillips, op. cit., note 55 above, p. 709. Among the work Phillips might have cited was research by Crane, Riklis and Quastel, Schultz and Curran, and Fisher and Parsons.

59) Not only did Phillips neglect to mention physiological work about the coupling of glucose and salt, he presented an alternative explanation for his observation of $\mathrm{Na}+$ and $\mathrm{Cl}-$ ions being absorbed with water and glucose. This further fortifies the earlier suggestion that the work of the sugar physiologists had not led Phillips to choose glucose for his solution. See note 47 and Phillips, op. cit., note 55 above, p. 712.

(1) Phillips, op. cit., note 55 above, p. 712 . Importantly, Phillips also showed that bicarbonate and potassium were absorbable in cholera patients even without the presence of glucose.

"I Ibid.

(2) Ibid. 
Thus, although the mode of practical implementation of a glucose-sodium solution had been an overall failure, even Phillips recognized that his work outlined the possibility for an effective therapy. While he saw the potential for oral therapy, he could not and would not overcome his shock from the Philippines. In the four ensuing years oral therapy research was significantly slowed down and even threatened by Phillips' trauma.

\section{DIARRHOEAL TREATMENT IN THE EARLY 1960s}

By the mid-1960s, Phillips was not the only supporter of careful balance studies with fluid therapies. Other doctors were acutely aware that fluid therapy, if improperly administered, could do more harm than good. An article published in 1964 mentioned that incorrectly administered therapy could result in death. ${ }^{63}$ In spite of this danger, the authors proceeded to state that children could be given oral therapy to supplement intravenous therapy and eventually work their way into oral maintenance therapy without intravenous solution. Consequently, it appears that doctors continued to view oral therapy as the transition between parenteral therapy and feeding for which Darrow had designed it. Two other U.S. physicians that year wrote that "There can never be an exact answer to this question [of glucose-salt proportions] for the particular patient to be treated, nor is there any laboratory test that can be done easily and quickly enough to provide an answer to this question in a clinical situation". ${ }^{64}$ Therefore, despite their advocacy of a therapy consisting of sodium chloride and glucose, they did not believe that there existed one ideal rehydration solution. Given the unique circumstances of each patient, there could be no specific formula. Clearly, the concept of oral rehydration was in the air, but its precise form evaded discovery.

\section{THE CHOLERA RESEARCH LABORATORY}

In December 1960, the Pakistan-SEATO Cholera Research Laboratory opened in Dacca, East Pakistan. ${ }^{65}$ During its first two years, the laboratory produced very little substantial work. By 1962, some individuals at the National Institutes for Health, which funded the laboratory in part, had learned of Phillips' work in the Philippines and recognized the potential for creating an oral therapy. Prior to leaving for Dacca in 1962, Greenough, a cholera physiologist, discussed oral rehydration with Dr Joseph Smadel, who worked under the director of NIH. According to Greenough, Smadel told him "that there was a possibility from the Navy work [Phillips' work in the Philippines] that one could treat cholera patients with oral rehydration solutions". The suggestion left Greenough rather miffed because "having at that point read something about cholera and the amount of fluid losses I thought that that [oral rehydration] was quite an outlandish idea". ${ }^{66}$ This encounter with Smadel reflects the paradoxical mental framework under

\footnotetext{
${ }^{6.3}$ Lewis A. Barness, MD, and Leighton N. Young, MD, 'A simplified view of hluid therapy', Pediatr. Clin. North Am., 1964, 2 (1): 3-15, p. 3. Nevertheless, public health workers in Mexico and Venezuela were increasingly using glucose-sodium oral solutions. See A. Yankauer and N. K. Ordway, 'Combating diarrhoeal discase in Latin America', WHO chronicle, 1964, 18 (7): 26()-4, on pp. 262, 264.

${ }^{64}$ Saul W. Bruislow, MD, and Robert E. Cooke, MD, 'Fluid therapy of diarrhea and vomiting', Pediatr. Clin. North Am., 1964, 11 (4): 889-9()1, on p. 89().

${ }^{6.5}$ SEATO proceedings of the conference on cholera, December 1960. Dacca, East Pakistan, Bangkok, The Post Publishing Co. Ltd., 1962.

(6) Greenough, interview, 10) January 1992, transcript p. 1.
} 


\section{The history of oral rehydration therapy.}

which cholera researchers operated at the time. On the one hand, they "recognized that intravenous hydration was not a solution to the problems in the field 'cause it was too restrictive and expensive to use in the situation where cholera occurred" and therefore worked toward a non-intravenous therapy. On the other hand, most researchers readily admit that even the concept of an oral therapy through the late 1960s "was quite unbelievable to most people". ${ }^{67}$

When Greenough arrived at the laboratory, untreated villagers with cholera had a 30 to 40 per cent mortality rate. As at that time the only cholera treatment considered acceptable was intravenous therapy, the researchers at the laboratory were developing ways to treat large numbers of people in the field with it. ${ }^{68}$ Given the morbid situation, Greenough and the others concentrated on improving the parenteral therapy and on finding ways to shorten the duration of the cholera. They therefore closely monitored the fluid intake and output of the patients and attempted to implement and modify Phillips' parenteral solution that had maintained such impressively low mortality rates in past cholera epidemics. Within one year Greenough and the staff had brought the mortality rate in the hospital down to under 1 per cent. ${ }^{69}$ With the cholera situation under control, the laboratory could then begin to expand its efforts and investigate the physiology of cholera and electrolyte transport in the gut. At that time, the leadership of the laboratory recruited Dr Hirschhorn and others to go to Dacca. ${ }^{70}$

When Hirschhorn arrived, Greenough and his colleagues were studying the defects in the epithelial transport system that cholera impaired. Initially, Hirschhorn concentrated on the relationship between cholera and intestinal enzymes. ${ }^{71}$ Soon after, Phillips came to take command of the Cholera Research Laboratory. His experience in the Philippines still weighed heavily on him and therefore he "had a very conservative view about continuing any human research on oral rehydration therapy". ${ }^{72}$ Nevertheless, the interest of his staff in oral rehydration was very high although they still viewed it principally as an intermediate step between parenteral therapy and feeding. ${ }^{73}$ Moreover, they believed it would be a potential treatment for adult cholera patients only. According to Hirschhorn, "Nobody thought about this [oral rehydration] for children and for diarrhoea other than cholera [even] in 1965 and 1966". ${ }^{74}$ Unlike scientists in the United States and Europe, the researchers at the Cholera Research Laboratory had a narrow conception of diarrhoea, for them it usually signified cholera.

Another important figure in the discovery of ORT, Dr David B. Sachar, arrived in Dacca in 1965. Sachar contends that at the time "the prevailing theory was that the secretory diarrhoea of cholera represented paralysis of the sodium pump". ${ }^{75}$ Essentially,

\footnotetext{
${ }^{67}$ Ibid., p. 3.

ax Ibid., p. 1.

(1) Greenough, personal communication, 11 March 1992.

70) Greenough, interview, 5 February 1992, transcript p. 2.

71 Ibid., p. 3.

72 Mosley, interview, 25 February 1992, transcript p. 2.

${ }^{7.3}$ The staff"s attitude mirrors Darrow`s view of oral rehydration from over a decade earlier. The researchers" concern for oral therapy suggests that while their rationale and physiological knowledge pointed toward it only as an intermediate treatment, they intuitively felt that it could serve a greater purpose.

${ }^{74}$ Hirschhorn, interview, 10 January 1992, transcript p. 3.

${ }^{75}$ Dr David Sachar, interview, 29 February 1992, transcript p. 2.
} 
cholera treatment ideology had not changed since Phillips' studies in late 1962. The clinical director of NIH at that time, Dr Robert Gordon, was very interested in verifying Phillips' hypothesis of the poisoned sodium pump. In the words of Sachar, he believed "that if there were a way to measure the electric potential inside the lumen of the intestine, that the theory of sodium pump paralysis could be supported by finding a loss of the normal negative potential". Gordon assigned the task to Sachar, who, with the help of Phillips, went to Copenhagen to design an experimental apparatus with a friend of Phillips, the distinguished physiologist, H. H. Ussing. ${ }^{76}$

They were successful, and Sachar returned to Dacca in March 1966 with an apparatus. ${ }^{77}$ An article by the British physiologists R. J. C. Barry and D. H. Smyth, which had shown that an actively transported sugar in a rabbit increased the negative potential across the gut, inspired Sachar to test his system similarly. It would be the first time this experiment had been carried out on a human sick with cholera. ${ }^{78}$ Sachar did not know of any therapeutic implications that the observations of Barry and Smyth might have for cholera, he wished to show only that the test he had designed would work. During the autumn of 1966 the experiment succeeded in showing an increase in negative potential, and Sachar and his associates "were really thrilled, dancing around the test lab" ${ }^{79}$ However, the group was excited only because the apparatus had worked. Its implications were not immediately apparent.

\section{THE FALL OF THE POISONED SODIUM PUMP HYPOTHESIS}

Soon after the experiment, Sachar and his colleagues collaborated with Hirschhorn and recognized that they had disproved the paralysed sodium pump hypothesis; they had made a breakthrough in physiology relevant to cholera-induced dehydration. ${ }^{80}$ In one sense, Sachar's Dacca work had not accomplished anything revolutionary. It did not define a new physiological mechanism, it simply demonstrated that an already defined mechanism worked in humans sick with cholera as well as in animals. The article describing the experiment stated that "The diarrhoea in this disease [cholera] is, therefore produced by a mechanism which does not substantially alter the normal intestinal transmural electric potential, and the intestinal capacity for sugar-dependent sodium transport probably remains intact". ${ }^{81}$ Phillips had originally believed that cholera patients should be treated with his oral sugar-electrolyte cocktail after he observed enhanced sodium absorption. The poisoned sodium pump hypothesis guided Phillips' experimental trial and tragedy. Sachar's work brought cholera research right back to where Phillips had been four years

\footnotetext{
76 Ibid., p. 2.

${ }^{77}$ Prior to arriving in Dacca in 1965, Sachar had met Schultz and Zalusky at the Harvard Biophysics laboratory, who helped him "understand a little better how enhanced glucose-linked sodium absorption would be reflected in an increased transmural electric potential". In spite of this Harvard connection, Sachar does not cite this interaction as having been a crucial influence on his experiment. Ibid., p. 3.

${ }^{78}$ Schultz, et al. had demonstrated that the electric potential would rise in animals, the very same work that Barry and Smyth had done. Ibid., p. 3.

${ }^{79}$ Ibid., p. 2.

${ }^{80)}$ Ibid., p. 2. The significance of the increased electrical potential was that it was a "reflection of the enhanced active sodium transport out of the lumen into the circulation". Ibid., p. 3.

${ }^{8}$ ' David B. Sachar, James O. Taylor, J. R. Saha, R. A. Phillips, 'Intestinal transmural electric potential and its response to glucose in acute and convalescent cholera', Gastroenterology, 1969, 56 (3): 512-21, on p. 512.
} 


\section{The history of oral rehydration therapy}

earlier, before the cocktail was used. ${ }^{82}$ The researchers in Dacca now knew of two points crucial for oral therapy: first, that glucose probably improved sodium and water absortion in cholera patients, and, second, that the paralysed pump hypothesis was false. Sachar's demonstration had immediate positive implications for cholera research.

\section{HIRSCHHORN TAKES CHARGE}

When Hirschhorn saw the initial results of Sachar's experiment, he quickly perceived the link to Phillips' earlier work in the Philippines. ${ }^{83} \mathrm{He}$ told Sachar that he wanted to move forward immediately to a clinical test in order to confirm that net positive fluid balance could be achieved with glucose and sodium solutions. Sachar felt that Hirschhorn was far too impatient and that such a trial would be "premature". ${ }^{84}$ So Hirschhorn had to "fight" both Sachar and Phillips in order to run his therapeutic application. ${ }^{85}$ Hirschhorn himself adds temporal and practical factors to his race for a clinical trial; he asserts that in the autumn of 1966 the laboratory was running low on intravenous fluids, the number of cholera patients was increasing, and they therefore had no choice but to move ahead with oral therapy-related studies. ${ }^{86}$

While Sachar hesitantly accepted Hirschhorn's appeal, Phillips posed a much greater block to the process. He had, for all intents and purposes, instituted a moratorium on all experimentation which related to oral therapy. Hirschhorn asserts that it was only when it appeared that the laboratory would have to come up with an alternative therapy that Phillips allowed the work to continue, and only if Hirschhorn proceeded cautiously. ${ }^{87}$ The study which he carried out was similar to Phillips' 1962 disaster except that this time the process was based on proven physiological principles. The solution was isotonic and the patients were monitored with advanced laboratory equipment. Eight cholera cases were admitted to the study, all of whom were in shock upon admission. The study utilized two approaches to perfusing fluid. Six of the patients received the electrolyte fluid intragastrically while the others received intestinal perfusions through multi-luminal tubing. The researchers maintained intravenous fluids throughout treatment and perfused

\footnotetext{
82 The influence of Phillips, at least in the medical literature, was often explicitly stated. Sachar noted in this article that "the therapeutic implications of this hypothesis [that the sodium pump remains intact in cholera] were first proposed by Phillips". Ibid., p. 519.

${ }^{8,3}$ Seal relates a dramatic story in which Phillips, after discussing Hirschhorn's proposed trial, locked the door and showed Hirschhorn the results of the fatal trial in the Philippines (van Heyningen and Seal, op. cit., note 6 above, p. 234). Phillips' secrecy slowed oral therapy research by blocking experimentation and the communication of pertinent information as well. Hirschhorn states that he saw the notes from Manila in October or November of 1966-virtually at the same time as Sachar's work. Hirschhorn, personal communication, 11 April 1994.

${ }^{8+}$ Sachar, interview, 29 February 1992, transcript p. 2. It is remarkable that van Heyningen and Seal neglect to mention the early work of Sachar. According to them, the revelation of the work in Manila alone inspired Hirschhorn to pursue his research. Moreover, they imply that it was Hirschhorn's work that had encouraged Sachar. This inaccurate presentation of events detracts from the impressive sequential chronology of the studies in Dacca. See van Heyningen and Seal, op. cit., note 6 above, pp. 234-6.

${ }^{85}$ Sachar, ibid., p. 8.

"60 Hirschhorn, interview, 10 January 1992, transcript p. 3.

${ }^{87}$ Ibid., pp. 3-4. Hirschhorn's viewpoint suggests that Phillips foresaw some type of practical therapy being born out of this experiment. Nalin contests this point and asserts that Hirschhorn was able to move forward only by premising the study on its physiological, not its practical, basis. Nalin, interview, 14 February 1992 , transcript p. 4.
} 


\section{Joshua Nalibow Ruxin}

one litre of solution per hour regardless of output. ${ }^{88}$ The solution, therefore, was not meant as a practical therapy that could be introduced in the field, since the patients had tubes in their stomachs and intestinal tracts; the researchers set out to lay the groundwork for oral therapy.

The results of Hirschhorn's study, carried out between November 1966 and March 1967, showed that a glucose solution always lowered the net stool output (indicating net absorption) and that a solution without glucose invariably increased it. ${ }^{89}$ Effectively, the study confirmed the work that Phillips had done in 1962 and published in $1964 .^{90}$ The researchers cautiously concluded that "oral glucose therapy could be of value in the treatment of cholera and that the requirement for expensive and scarce intravenous fluids may be reduced thereby". 91 They limited their conclusion to cholera since they could not imagine using such a treatment on other patients. People were dying from cholera in far off areas, where intravenous treatment could not be supplied, and they wanted a therapy for them. Although Hirschhorn recognized some of the practical applications that Sachar's work and the follow-up had suggested, he could not foresee its major implications.

At this point, however, there were physicians who saw the full potential of oral therapy. At a presentation of Hirschhorn's findings in Dacca, one of the plantation doctors, $\mathrm{Dr}$ Mackay, responded ecstatically.

He [Dr Mackay] got up and said "This is one of the most profound developments in the treatment of . . . cholera diarrhoea this century". And I remember being a little startled by that and saying to myself ... "gosh, maybe he's right". But we had come at it [cholera] in terms of this [being] a really amazing scientific finding and it was based on true physiology ... we were also preparing ourselves for using it as an emergency measure when we ran out of IV fluids. We were not yet saying that this would be a great thing to put into a village. It seemed like this was something we could use as an emergency backup. ${ }^{92}$

Perhaps it is due to such experiences that Hirschhorn asserts that his balance studies, along with the work which demonstrated that cholera allowed co-transport to function, signified the point at which the physiological basis for oral therapy had been discovered. ${ }^{93}$

Even after the successful study of decreased stool output, Hirschhorn remained pessimistic about the future of oral therapy research, partly because he paid meticulous attention to every indicator, and this intensive analysis made him question whether there would ever be a practical basis for oral therapy. ${ }^{94}$ Hirschhorn believed that he had

\footnotetext{
${ }^{88}$ Norbert Hirschhorn, Joseph L. Kinzie, David B. Sachar, Robert S. Northrup, James O. Taylor, S. Zafar Ahmad, and Robert A. Philips, 'Decrease in net stool output in cholera during intestinal perfusion with glucosecontaining solutions', N. Engl. J. Med., 25 July 1968, 176-81, on pp. 176-7. The title of this article and others related to this topic could deceive readers unfamiliar with the experimentation since they imply that the stool output decreased with intake of glucose-sodium solutions. In fact, the stool output might increase as more solution is ingested. The crucial point is that the net amount, the solution ingested subtracted by the stool plus any vomitus, was positive. Thus, although there may have been more fluid expelled from the body than before treatment, overall the intestines absorbed more than was lost.

"Ibid.

${ }^{90}$ Nalin, interview, 14 February 1992, transcript p. 3.

${ }^{91}$ Hirschhorn, et al., op. cit., note 88 above, p. 176.

${ }^{92}$ Hirschhorn, 10 January 1992, transcript p. 6.

9.3 Ibid., p. 8.

94 Ibid., p. 4.
} 
completed the groundwork for it, but that the therapy still did not exist as a distinct entity and might never be feasible. One researcher suggests that the use of nasogastric and multiluminal tubes in Hirschhorn's experiment severely limited even consideration of its practical potential. ${ }^{95}$ The members of the research team used these tubes to make precise physiological observations and because they did not believe that a patient could drink the quantities needed for adequate rehydration. Although the physiological basis for oral rehydration had been demonstrated, the composition of a practical therapeutic regimen remained elusive.

\section{PROGRESS IN CALCUTTA}

Hirschhorn was not alone in his balance studies in 1967. The Johns Hopkins Center for Medical Research and Training in Calcutta, which had been established at roughly the same time as the Cholera Research Laboratory in Dacca, was working on similar issues. While some say the relationship between the laboratories was friendly, recently the two groups have vied for credit, especially in the area of oral rehydration therapy. ${ }^{96}$ The Calcutta group visited Dacca and observed Hirschhorn's work. Led by Nathaniel F. Pierce, they substantially improved the experimental design and conducted a study between May and July 1967..$^{97}$ The Indian Journal of Medical Research published their findings two months before Hirschhorn's appeared in print. ${ }^{98}$

Although the study by Pierce and others contained conclusions that mirrored those of Hirschhorn, a close comparison of the apparatuses reveals the substantial improvements made by the Johns Hopkins Center. All the glucose solutions were perfused intragastrically at a rate which exceeded stool output by 100 to $200 \mathrm{ml}$ per hour, whereas Hirschhorn's procedure had prescribed one litre per hour regardless of output. ${ }^{99}$ Additionally, Pierce and his team systematically varied the glucose-sodium ratios, thereby providing important knowledge about effective glucose levels. Furthermore, the Calcutta study stopped supplemental intravenous therapy on some of the patients, indicating greater confidence in the effectiveness of the glucose solution, and thereby being the first to show that cholera patients could be hydrated (for at least twelve hours) by an intragastric glucose solution alone. ${ }^{1(0)}$ Essentially, the Calcutta experiment advanced Hirschhorn's

\footnotetext{
"s Mosley, interview, 25 February 1992, transcript p. 2.

"However, unlike the stereotypical cutthroat competition of today, the two laboratories freely shared their results.

${ }^{97}$ Nathaniel F. Pierce, personal correspondence, 20 April 1994.

"Pierce states that researchers were widely discussing glucose-sodium solution to rehydrate cholera patients during the summer of 1966 and that it was then that he decided to carry out an experiment. Ironically, he, like Hirschhorn, suggested the idea to Phillips and received an unenthusiastic response. Nathaniel F. Pierce, personal correspondence, 16 November 1993.

"T) The Calcutta study did not use the impractical multi-liminal tubing Hirschhorn had utilized.

${ }^{I(x)}$ N. F. Pierce, et al., 'Oral maintenance of water-electrolyte and acid-base balance in cholera: a preliminary report', Ind. J., med. Res., 1968, 56 (5): 640-5. See also, Nathaniel F. Pierce, et al., 'Effect of intragastric glucose-electrolyte infusion upon water and electrolyte balance in Asiatic cholera', Gastroenterology, 1968,55 (3): 333-43. Nathaniel F. Pierce, personal correspondence, 16 November 1993. Some dispute the chronology of the experiments. Dr Charles C. J. Carpenter explicitly stated in reference to Hirschhorn's experiments that "They |the Cholera Research Laboratory] did parallel studies shortly after Dr Pierce did them". Carpenter, interview, 21 February 1992, transcript p. 2. In a separate interview, on the same topic, Carpenter said, "I think that the study that Bert Hirschhorn did at Dacca was done virtually simultaneously with the ones they did in Calcutta; and they were both very important. I think that Nate's [Pierce's] was a little more meticulous; he had a better set-up and the sense to do it, I don 't think any particular additional credit derives to him for doing it first".
} 


\section{Joshua Nalibow Ruxin}

framework and made an important contribution to the feasibility of an oral glucose solution. The conclusions reached by both groups were reinforced tremendously by their independently concordant results. Their work demonstrated that Phillips' observation had not been an anomaly and carried the promise for a practical oral rehydration therapy a great step ahead. ${ }^{101}$

With the scientific groundwork laid for ORT, one might expect that a practical therapy, or at least experiments on oral therapy would have followed immediately. On the contrary, oral rehydration-related work slowed because the researchers had to wait for the next cholera season. According to Henry Mosley, the chief epidemiologist in Dacca at the time, Phillips felt that the research questions had been answered and that therefore, the Dacca team's work with oral therapy had been completed. ${ }^{102}$ Hirschhorn attributes Phillips' "change of heart" to the kinship bonds he felt for those doctors with whom he worked. After his experiment and a trip to the United States, Hirschhorn had intended to return to Dacca, but his visa was not approved. ${ }^{103}$ Phillips, who had confidence in him, "didn't quite trust the next crew that came along", ${ }^{104}$ and with Hirschhorn absent from the laboratory, much of the inspiration for progress toward an oral therapy faded.

\section{THE REINS ARE PASSED}

The crew that arrived in August 1967 consisted of Drs Richard Cash and David Nalin. At the time, Nalin, twenty-six years of age, had completed only the first year of his medical residency when the international research office at the National Institutes of Health assigned him to Dacca. Nalin was told only that he would be working on clinical research on cholera. ${ }^{105}$ Cash, also twenty-six, had just finished his internship in surgery and had become a U.S. Public Health Service Officer. The National Institute for Allergies and Infectious Disease assigned him to Dacca. Neither doctor had had any previous experience with cholera or epidemic diarrhoea. ${ }^{106}$

There was some continuity between the old guard at the laboratory and the new. Before arriving in Dacca, Nalin and Cash heard Hirschhorn and Pierce present their findings at a cholera symposium in Palo Alto, California, in July 1967. Hirschhorn's study came under the heading 'Pathophysiologic studies in man and in animals' rather than a title which which might have suggested a practical component of the work. ${ }^{107}$ Nalin's and Cash's reactions were that the physiological work and the possibility for oral therapy were "interesting" but unfeasible. ${ }^{108}$ Nalin felt that there was "absolutely no one who believed that an oral therapy could work as a practical thing in rural areas or even in hospitals". In

Thus, although Carpenter generally suggests that the studies occurred at the same time, he incorrectly believes that Pierce completed the trial first. Carpenter, interview, 27 February 1992, transcript p. 3.

101 In Cholera van Heyningen and Seal fail to differentiate between Hirschhorn's study and Pierce's. They imply that the work progressed independently and produced identical conclusions. Op. cit., note 6 above, pp. 236-7.

${ }^{102}$ Mosley, interview, 25 February 1992, transcript p. 2.

${ }^{103}$ Hirschhorn, interview, 10 January 1992, transcript p. 6.

104 Ibid., p. 4.

105 Nalin, interview, 14 February 1992, transcript p. 1.

$106 \mathrm{Nalin}$ and Cash were required to serve in some governmental capacity because of the Vietnam War. Cash, personal communication, 1 April 1992.

107 'Symposium on cholera', Palo Alto, California, July 26-28, 1967 (unpublished document). Pierce and his associates referred to their study as oral maintenance.

${ }^{108}$ Nalin, interview, 14 February 1992, transcript p. 2. 


\section{The history of oral rehydration therapy}

physical terms alone he could not comprehend how a patient in shock could possibly drink one litre of oral rehydration therapy per hour for twenty-four hours, especially without modern equipment and medical personnel. ${ }^{109}$

\section{THE CHITTAGONG PROTOCOL}

In late September 1967 cholera broke out in the Chittagong district of East Pakistan, along the Burmese border. Dr Olson, the Director of the Christian Mission Hospital in Malumghat, requested assistance from the laboratory. ${ }^{110}$ Nalin and Cash travelled to the site to help establish a clinic for the victims and to carry out studies of their own. At roughly the same time, Dr James Taylor, a senior investigator at the laboratory, asked Dr Rafiqul Islam, a young, local investigator from the laboratory, to write a short oral therapy protocol. When the treatment centre was established, Kendrick Hare, the director of the Cholera Research Laboratory under Phillips, and Ruth Hare, the head of the biochemistry laboratory, assigned Nalin to oversee Islam's protocol. ${ }^{111}$ Although Phillips was out of the country for at least part of the time when the protocol was executed, Nalin concedes that, despite Phillips' "cold feet" on oral therapy, "he was willing to test the waters [with this protocol]". 12 None the less, Nalin asserts that Phillips "probably thought that he would never let it [the protocol] get developed to a full practical extent". 113 The manner in which this protocol had come into existence supports this assertion. Rafiqul Islam believes that his designation as author, along with other local, less experienced investigators, indicated the weak commitment to oral rehydration therapy by the Cholera Research Laboratory. ${ }^{114}$

The protocol which Islam and others executed between October and November 1967 failed to demonstrate the efficacy of an oral therapy. Although there were no deaths, most of the patients became overhydrated or remained dehydrated on the treatment. There was one major flaw in the formula of the protocol; it called for one litre of the glucose therapy to be given intragastrically to patients every hour (for the first eight hours) regardless of output data. ${ }^{115}$ A patient who excreted 250 millilitres per hour was therefore given the same amount of rehydration fluid as a patient who excreted 1,250 millilitres per hour. The protocol distinctly paralleled the study by Phillips in the Philippines where data regarding intake and output were also overlooked and did not correlate to the treatment.

The underlying feature that Phillips' Philippine study shared with this failed protocol was that both searched for a magic bullet for choleraic dehydration. The investigators who

(10) Ibid.

${ }^{110}$ Dr Rafiqul Islam, personal correspondence, 23 August 1993.

111 Nalin, personal communication, 2 April 1992. Also Islam, personal correspondence, 23 August 1993. While the designation of Nalin to oversee the protocol intimates a substantial commitment on the part of the laboratory to practical oral therapy, Nalin was totally unfamiliar with cholera and diarrhoea at the time. Thus, he was one of the weakest choices. Others at the laboratory were carrying out highly advanced metabolic studies and would have been more suitable to analyse and manage the protocol.

112 Nalin, interview, 14 February 1992, transcript p. 11.

11.3 Ibid. There was a technical advisory committee, consisting of high-ranking officials from NIH and the CDC, which wanted further work to be carried out on oral therapy. The development of this first protocol appears to have been a token gesture to placate the interest of the staff in practical experimentation.

$1{ }^{14}$ Nalin's supervisory role of the protocol written by Islam was meant to be peripheral. Islam, personal correspondence, 23 August 1993, and personal communication, 24 August 1993.

115 Dr Rafiqul Islam and P-SCRL Ward Physicians, 'Research protocol: oral lavage of a solution containing glucose, electrolytes and tetracycline as a method of treatment in acute cholera', unpublished document, in notes of Pakistan-SEATO Cholera Research Laboratory Technical Committee meeting 27-29 November, 1967. 


\section{Joshua Nalibow Ruxin}

designed the studies believed that the oral solution would have to function in terrible, primitive conditions and would therefore have to consist of one universal form and quantity. ${ }^{116}$ The Chittagong protocol demonstrates that the authors could not conceive of untrained villagers or public health workers knowing how much solution to give the cholera patients. They therefore decided on an arbitrary amount, one litre, and hoped for success. Likewise, Hirschhorn's study involved perfusing the glucose solution at the rate of one litre per hour, regardless of net output. ${ }^{117}$ This similarity suggests that the work completed by Hirschhorn was the basis for the protocol. Islam recalls writing the protocol under the guidance of Taylor and using Hirschhorn's and Phillips' earlier work as the "basic guidelines". ${ }^{18}$ Thus Islam and the other investigators mistook Hirschhorn's purely physiological study for a practical one. Hirschhorn had set out to clarify and confirm the 1962 findings of Phillips; he did not create a practical treatment. ${ }^{19}$ Had Islam and the others used the latest study by Pierce as the basis for the protocol, it is likely that the experiment would have been a success.

Upon the failure of the Chittagong protocol, Nalin had the opportunity to analyse the results. After looking at the findings, he did not simply label oral therapy as unusable. Had he done so, it might have been many months or even a couple years before researchers developed an effective oral rehydration regimen. Nalin remembers "sitting in a tent and going over the data from the failed ... study and ... very clearly suddenly realizing that this had to work and also having the feeling that it was very important to make it work". ${ }^{120}$ He asserts that he realized precisely what went wrong with the Chittagong study and understood that if the dosage of the therapy corresponded to intake and output measurements then it would be "a sure fire success". ${ }^{121}$ Having spent months in the jungle where intravenous therapy could not be used efficiently or effectively, he recognized "how important this would be for these people [in the jungle]". ${ }^{122}$ Nalin and Cash returned to Dacca in December 1967, determined to carry out a revised clinical trial based on Nalin's new, second protocol. ${ }^{123}$ They knew, however, that they would have to wait a few months for the spring cholera outbreak.

\section{THE SECOND PROTOCOL}

In Dacca, Phillips learned of the failed protocol and then responded with great pessimism to Nalin's and Cash's desire to forge ahead. While Phillips evidently did not

${ }^{116}$ Nalin, interview, 4 February 1992, p. 4.

${ }^{117}$ Hirschhorn et al., op. cit., note 88 above, p. 176.

118 Islam, personal correspondence, 23 August 1993.

119 According to Sachar, the study with Hirschhorn was impractical because "We didn't develop that protocol as an optimal therapeutic regimen; it was just a metabolic study, to determine a yes-or-no phenomenon, to shift the patient from negative balance to positive balance. And the logical way to do that, when you're doing a metabolic study, as opposed to making up a treatment protocol, is to use a fixed dose", Sachar, interview, 29 February 1992, transcript p. 7.

${ }^{120}$ Nalin, interview, 14 February 1992, transcript p. 5.

121 Ibid. Nalin relates that an important new change made in his protocol was to match oral solution volume to the volume of diarrhoea plus vomitus of the previous four or six hour period. This ensured maintenance of water and electrolyte balance. Nalin, written comments, April 1994.

122 Nalin, interview, 14 February 1992, transcript p. 5.

12.3 Islam states that Nalin ignored "me and my other national colleagues . . Being local young researchers, we could not raise our voice against expatriate's decision". Islam, personal correspondence, 23 August 1993. Nevertheless, Islam would later be listed as a co-author of Nalin's protocol. 
stop the new protocol from being carried out, it was executed only when he had left the country on a trip. The Cholera Research Laboratory policy dictated that in Phillips' absence, the deputy director, Kendrick Hare, would be acting director, and he enthusiastically allowed the second protocol a clinical trial. It can be conjectured that he consulted Phillips beforehand, and, since they were old friends, Phillips approved it.

Whatever the case, Nalin, Cash, Islam, Molla (another local investigator), nursing supervisor Torrance, and nurses Bashonti, Gomes, Gafur, and Margaret executed the second protocol in the Cholera Research Laboratory hospital in Dacca. ${ }^{124}$ The protocol signified the first time a glucose maintenance solution had been given by mouth since Phillips' failed protocol six years earlier. The researchers utilized every available safeguard; additionally, Cash or Nalin was always right next door in case problems arose. ${ }^{125}$ In an effort to demonstrate the effectiveness of the therapy in the most severely ill patients, the researchers accepted only patients who arrived in a state of shock. ${ }^{126}$ They then gave them just enough intravenous therapy to achieve a stable pulse rate and begin oral treatment. Nalin was the driving force for the exclusive use of oral therapy in the experiment. ${ }^{127}$ Islam recalls "When we saw a patient, we hesitated just to allow the patients on oral therapy alone... unless we started IV we feared the patients' deaths. Nalin had a stronger belief [in the therapy] than [we did]. The other local doctors and I had hesitation ... [Nalin] was reluctant [to restart IV] when, after initial IV hydration, output increased and we [the local doctors and nurses] wanted to restart IV". ${ }^{28}$ Nalin's perseverance resulted in unparalleled success. For the first time, a glucose-sodium solution alone, given only by mouth, maintained water and electrolyte balance during cholera. After treating several patients, all the researchers recognized they had been successful; they had reduced the usage of intravenous solutions by 80 per cent, even in these critically ill patients. ${ }^{129}$

Nalin and Cash treated the first patients in this study during April 1968 and the Lancet published the results in August. In the article they concluded that "an oral solution

${ }^{124}$ Dr Abdul Majid Molla, personal correspondence, 23 August 1993.

${ }^{25}$ Nalin, interview, 14 February 1992, transcript p. 6. David Nalin, 'Clinical trial of an oral therapeutic solution for acute cholera in adults", unpublished document. In this trial protocol the oral infusion rate depends on net stool output and vomitus; it is not a fixed rate as in the unsuccessful protocol. Not only was Cash"s or Nalin`s presence necessary in case of an emergency, but also to ensure scientific accuracy. The other doctors and nurses who monitored the patients did not trust the oral solution and sometimes turned on the intravenous drip for patients who were taking it without justification related to hydration status. Nalin, written comments, April 1994.

126 Generally, those patients who had no determinable pulse in their radial artery were considered to be in shock. They generally required IV therapy equivalent to 10 per cent of body weight at the time of admission. Nalin, written comments, April 1994.

127 This therapy cannot accurately be labelled oral rehydration therapy since IV therapy rehydrated the patients. The oral glucose solution maintained their hydration status and should therefore be referred to as oral maintenance therapy.

${ }^{12 x}$ Islam, personal interview, 24 August 1993.

${ }^{129}$ Nalin's protocol called for 4.22 grams of $\mathrm{NaCl}, .5$ gram of $\mathrm{KCl}, 4$ grams of $\mathrm{NaHCO}_{3}$, and 20 grams of glucose mixed in one litre of water. The WHO's official formula today is based on the formula used in Calcutta and consists of 3.5 grams $\mathrm{NaCl}, 1.5$ grams KCl, 2.5 grams $\mathrm{NaHCO}_{3}$, and 20 grams of glucose dissolved in one litre of water. Van Heyningen and Seal allocated two sentences to Nalin`s revision and neglected to mention the breakthrough from orogastric tubes to oral administration. Thus the first practical ORT trial is poorly documented in their book-according to the text, no significant breakthrough was made in April 1968. Op .cit., note 6 above. pp. 237-8. 


\section{Joshua Nalibow Ruxin}

containing glucose and electrolytes can eliminate the need for over three-quarters of the intravenous-fluid requirement in the therapy of acute cholera in adults". However, they stopped short of advocating their therapy in all situations, claiming that although "mild cases of cholera [without shock] may be treated with oral solution alone", "specially trained staff" were still needed to oversee patients being treated with oral therapy. ${ }^{130}$ Oral therapy worked, but it had only been proved effective in a meticulously controlled and monitored environment; the next step was to demonstrate its usefulness in the rural areas of East Pakistan where intravenous therapy was unavailable.

While oral therapy research moved forward, its proven utility caused the previously fairly subtle competition between the Dacca and Calcutta cholera laboratories to surface. After finishing the report for the second protocol, Nalin travelled to the Johns Hopkins research laboratory in Calcutta to share notes. ${ }^{131}$ Although the John Hopkins staff had advanced Hirschhorn's work a year earlier, they had not made the same progress as Nalin and Cash. ${ }^{132}$ Nalin claims "they greeted my news [of the second protocol] initially very hostilely and said it was reckless and irresponsible and would never be practical". ${ }^{133}$ Nalin does not attribute their reaction to jealousies or indifference, rather, he believes that the group in Calcutta was familiar with Phillips' failure and had been influenced by the "folklore" surrounding cholera. For example, since vomiting was a characteristic of the first few hours of the disease, these researchers could not imagine patients swallowing and holding down so much fluid. ${ }^{134}$ One month after Nalin's visit, Cash visited Calcutta and found the group carrying out an oral therapy protocol that utilized nasogastric tubing and tested the efficacy of a glucose-electrolyte solution. Then, at a conference in Teheran in August, Pierce approached Nalin and Cash and asked them whether they would be interested in co-publishing their results; Nalin replied that the results had already been published in the Lancet, and Pierce expressed disappointment. ${ }^{135}$

While there has been some disagreement about whether Calcutta's or Dacca's oral therapy study came first, the evidence overwhelmingly supports Dacca. ${ }^{136}$ Kendrick Hare sent Nalin's study in to the Lancet on 25 June 1968, and the editor approved it for publication on 2 July $1968 .^{137}$ Pierce's publication of his oral therapy experiment was

\footnotetext{
${ }^{130}$ David R. Nalin, Richard A. Cash, Rafiqul Islam, Majid Molla, Robert A. Phillips, 'Oral maintenance therapy for cholera in adults', Lancet, 1968 ii: 370-3, on pp. 370-2.

1.31 David Nalin, 'Dr. David Nalin's visit to Johns Hopkins CMRT, Calcutta', unpublished document, 13-17 May 1968.

1.32 Nalin does, however, point out that Nate Pierce had unsuccessfully tried another solution which substituted maltose for glucose. Nalin, interview, 14 February 1992, transcript p. 7.

1.3 .3 Ibid

1.34 Ibid.

1.35 Pierce, personal correspondence, 20 April 1994. According to Nalin and Cash, Pierce became agitated on this occasion and made critical remarks. Nalin, interview, 14 February 1992, transcript p. 8, and Cash, personal communication, February 1992.

${ }^{136}$ The only person I encountered who challenged the chronology of Nalin's and Cash's work was Charles C. J. Carpenter, who was in close contact with the Calcutta laboratory and was head of it in the early 1960). With regard to the first trial he states, "I don't know when he |Nalin| got there, so I can't corroborate anything about that, but I certainly do want to say that he doesn't seem accurate [in calling his the first|." Carpenter's words seem especially misleading since Pierce agrees with Nalin's chronology. Pierce, interview, 31 March 1992, and 27 February 1992, p. 2. See also note 100 above.

${ }^{1.37}$ Kendrick Hare, letter to the editor of the Lancet (unpublished document), 25 June 1968. Also, I. Douglas-Wilson, letter to David R. Nalin, unpublished document, 8 July 1968.
} 
based on work executed between May and July 1968 and expressed conclusions similar to those of Nalin and Cash. ${ }^{138}$ Pierce began the study only after Nalin's visit in mid-May 1968. ${ }^{139} \mathrm{He}$ affirms that "It would be unrealistic to state that the information provided by Dr Nalin during his visit did not affect our decision [to pursue glucose-based oral therapyl". He further emphasizes the importance of his work having confirmed that of Dacca. ${ }^{140}$ It must be noted, however, that the cholera seasons heavily influenced the timing of studies in both places. In Calcutta the season lasts from May to September, while in Dacca it spans November to February, often with a small outbreak in the spring. ${ }^{141}$ Considering this, the linearity of the experimentation is astounding. Sachar's spring 1966 study led to Hirschhorn's winter 1966 work which Pierce advanced in the summer of 1967. Inspired by Hirschhorn, Islam proceeded with the Chittagong protocol in the winter of 1967 which Nalin transformed into oral therapy during a spring outbreak in 1968. Pierce then confirmed Nalin's work in the summer of 1968. Thus, researchers in Calcutta and Dacca carried out substantive studies during every cholera season from 1966 through 1968.

Although Phillips was out of the country during the time of the second protocol, Nalin included his name on the study since he believed "that his earlier work justified it". ${ }^{142}$ When Phillips returned from his European trip, the entire laboratory was enthusiastically supporting their work. Although they had achieved success, Nalin and Cash realized that, without a trial which used the therapy in the field, the scientific community at large would remain unconvinced. They therefore began planning for a field trial of their oral therapy without requesting the help of Islam or Molla. ${ }^{143}$ Phillips openly discouraged their plans. Nalin speculates that Phillips, under the influence of his alcoholism, might have been dwelling on the tragic outcomes in the Philippines. ${ }^{144}$ Mosley disagrees and asserts that Phillips simply did not see Nalin's and Cash's proposal for a field trial as "real research". ${ }^{45}$ Additionally, Mosley states that Phillips might have worried that his clinical

\footnotetext{
${ }^{13 \times}$ Nathaniel F. Pierce, R. Bradley Sack, Rupak C. Mitra, John G. Banwell, Kenneth L. Brigham, David S. Fedson, Arabindo Mondal, 'Replacement of water and electrolyte losses in cholera by an oral glucose-electrolyte solution', Ann. Intern. Med., June 1969, received December 1968, 70 (5): 1173-81.

1.39) Van Heyningen and Seal present Carpenter's ambiguous version of the story. They state that when Pierce took over the laboratory in 1966, he began testing oral glucose-electrolyte solution, which leads the reader to believe that there was an oral therapy in 1966 and that it was first developed in Calcutta. This recapitulation of the story conveys a misunderstanding about the meaning of oral rehydration. For example, van Heyningen and Seal call the replication by Calcutta of Hirschhorn's work oral rehydration when, in fact, it was a metabolic study which did not constitute a practical therapy. Op. cit., note 6 above, pp. 236, 240.

${ }^{1+0}$ Pierce, personal correspondence, 20 April 1994, and personal interview (recorded), 31 March 1992. It is crucial to recognize that the study by Pierce had been planned between September 1967 and March 1968-before Nalin's visit and possibly before Nalin wrote the second protocol. However, the study as planned and conducted still used nasogastric tubes-it was not precisely a practical oral therapy. This supports the assertion by Pierce that Nalin only encouraged Calcutta to switch to a glucose-based oral therapy study. Pierce does not believe that "it [Nalin's visit] affected the design of the trial we carried out" (emphasis mine). Furthermore, Pierce recalls that, by Nalin's arrival, the maltose study already appeared inferior to IV therapy. He states, "we [in Calcutta] were aware that he [Nalin| and Dr Cash had completed an important clinical trial based on the previous year"s studies and we wanted to make every effort to complete at least one trial of our own during the 1968 season". Pierce, personal correspondence, 20 April 1994.

$1+1$ Nathaniel F. Pierce, personal correspondence, 16 November 1993.

$1+2$ Nalin, interview, 14 February 1992, transcript p. 12.

$1+3$ Islam, personal interview, 24 August 1993, also Molla, personal correspondence, 23 August 1993.

${ }^{1+4}$ Nalin, interview, 14 February 1992, transcript p. 12.

1+5 Mosley, interview, 25 February 1992, transcript p. 3.
} 


\section{Joshua Nalibow Ruxin}

researchers would be distracted from "making new discoveries" if they focused their efforts on practical applications. The data had convinced Phillips that oral therapy worked, but most people, including himself, still did not fully recognize its significance. ${ }^{146}$

\section{MATLAB}

In the autumn of 1968, Nalin and Cash wrote an oral rehydration therapy protocol to be carried out in the field, in Matlab Bazaar, rural East Pakistan. They aimed to carry out the trial not only to prove the effectiveness of their therapy, but also to best treat the epidemic in Matlab. In Matlab there would be a limited supply of intravenous solutions and there would be patients who, without oral rehydration therapy, might have no treatment whatsoever. Phillips responded negatively to their proposal and told them that they would not be permitted to execute it. Given the impending situation in Matlab, Nalin and Cash felt that they were encountering "irrational fears". Moreover, no one had given them a full account of the circumstances surrounding the five deaths in the Philippines, a lack of communication which certainly increased the mysteriousness of Phillips' negativity.

Finding Phillips to be totally intractable and having heard of a telegram from the National Institutes of Health that research should not continue, Nalin, Cash, and their supporters at the laboratory began discussing alternatives. One option was to ignore their orders and proceed with the study. However, they swiftly concluded that as Public Health Service Officers, they could thereby be subject to court martial. ${ }^{147}$ With this punishment and Phillips' attitude in mind, Nalin and Cash turned to Henry Mosley, the head of epidemiology at the Cholera Research Laboratory, for help.

Due to a previous arrangement, Mosley functioned autonomously at the Cholera Research Laboratory, and only had to obtain project approval from the Centers for Disease Control (CDC) and his superior at the Epidemiological Intelligence Service, Alex Langmuir. ${ }^{148}$ Mosley told Phillips that he wanted Nalin's and Cash's Matlab protocol performed. Mosley asserts that Phillips had no problems with the plan, provided that Nalin and Cash did not work on the project full time, and that his only reservation about the project initially had been that he did not want his clinical researchers working on practical field trials instead of research. Mosley wanted Nalin and Cash to play a major role in the trial since "they had been involved intimately with the development of the protocol ... and they were the ones that would be most capable of managing the project". ${ }^{149}$ Mosley therefore resolved initially to have two Epidemiological Intelligence Service officers sent to Dacca through the CDC. These doctors, under the direction of Nalin and Cash, would carry out the protocol in Matlab. Langmuir readily agreed to the plan, and Phillips expressed no further objection. The support Langmuir provided was crucial to the

\footnotetext{
146 Ibid.

${ }_{147}$ Nalin, interview, 14 February 1992, transcript p. 13, and personal correspondence, 26 March 1992.

${ }^{148}$ An explanation of Mosley's position at the Cholera Research Laboratory requires some backtracking. When Phillips joined the laboratory in 1965, he did so on the understanding he would have no involvement with epidemiology. The National Institutes for Health therefore called Alex Langmuir at the Centers for Disease Control (CDC) who gave Mosley the appointment of head of epidemiology. Mosley, interview, 25 February 1992, transcript p. 8.

149 Ibid., pp. 6, 7.
} 
implementation of the protocol, as Mosley explains, he "saw the world-wide impact of this, but the rest of us still didn't quite appreciate it". ${ }^{150}$

Langmuir, who communicated with Phillips frequently, says that he never comprehended just why Phillips did not desire to go ahead with the field trial. He corroborates Mosley's assertion that Phillips distinguished between the "applied research", which Nalin and Cash desired, and "basic fundamental research", which Phillips wanted them to do. ${ }^{151}$ Langmuir, however, believes that there might have been more to Phillips' resistance than this distinction:

\begin{abstract}
Part of this [resistance to the Matlab trial] also was a divided loyalty ... in Dr Phillips himself because he was the former chief of the lab in Taiwan (NAMRU-2), and they were working on this also. After all, they had been working on it first, before anything was even discussed in Dacca... and a divided interest is just not the way. He had a definite continuing loyalty to the work that was being done in Taiwan ... and [believed] they should have the opportunity to do the field test. ${ }^{152}$
\end{abstract}

Langmuir states that Phillips approved the trial, or "at least he didn't stop it". ${ }^{153}$ Both Mosley and Langmuir agree that although Phillips did not want the trial to go ahead in Dacca, he did not totally impede the process. Nevertheless, Nalin believes that there was something more to this resistance. He asserts that Phillips had an agreement with John Seal at the National Institutes for Health, and, at least initially, attempted to block the process. This interpretation of the situation is not inconsistent with the views of Langmuir and Mosley; however, they feel that Nalin has exaggerated Phillips' response. ${ }^{154}$ The involvement of Seal probably increased Nalin's perception of a threatening atmosphere. According to Nalin and others, Seal sent a menacing telegram in which he backed up Phillips (and was apparently inspired by previous communication with Phillips). ${ }^{155}$ This telegram has never been found. Seal claimed that he "cannot recollect such a cable, doubts that he would have used their [threatening] wording" and could not find it in any of his files. ${ }^{156}$ However, there is evidence of correspondence between Seal and Phillips on this very issue.

On 11 October 1968, Seal, in his capacity as Chairman of the NIH Cholera Advisory Committee, wrote a letter to Phillips which indicated ongoing discussion on the topic of the Matlab trial. By this time, Seal wrote, the request for health officers from Langmuir had already been filed, and Seal expressed some reservations about this after having read the article by Nalin and others on 'Oral maintenance therapy for cholera in adults' published in the Lancet. Seal responded very apprehensively to a cautionary sentence in the report which read, "We would emphasize that the continued need for intravenous therapy and for careful records of intake and output dictate that specially trained staff must

\footnotetext{
${ }^{150}$ Ibid., p. 8.

151 Dr Alexander Langmuir, interview, 28 February 1992, transcript p. 1.

152 Ibid.

15.3 Ibid.

154 Ibid., p. 4, and Mosley, interview. 25 February 1992, transcript p. 9.

155 Cash, op. cit., note 39 above, p. 12.

156 Van Heyningen and Seal, op. cit., note 6 above p. 238.
} 


\section{Joshua Nalibow Ruxin}

supervise the management of cholera patients who are on oral maintenance therapy". Seal concluded from this judicious comment that the Matlab trial should be placed on the back burner and "be reviewed in depth within the laboratory and by the Technical and Clinical Research Committees before decision". ${ }^{157}$ Seal desired to block the Matlab field study for at least a few months.

In conclusion Seal wrote, "It was evident during your [Phillips'] visit that I had misinterpreted your problem in the earlier letter and now I find myself not knowing whether you are or are not in favor of the oral therapy trial". ${ }^{158}$ Apparently, Phillips had conveyed some reservations about the project to Seal, but recent developments had rendered Phillips' opinion ambiguous. Seal therefore intimated that Phillips should convey what he wanted done with the study so that Seal could rubber stamp it. Whether or not Seal sent a menacing telegram, he evidently wanted the process halted for the time being, ${ }^{159}$ and although his words were not threatening, they were communicated in an official capacity. Furthermore, had the study gone to committee the epidemic would have passed and the opportunity to carry it out would have been delayed until the following cholera season, by which time Nalin would have returned to the United States. His term at the laboratory had not been renewed.

All the objections and insinuated threats which Phillips made to Cash and Nalin exhilarated and encouraged them to move ahead. In Nalin's words, "it showed us that there was a stick somewhere behind the carrot". ${ }^{160}$ Cash and Nalin, with their Bengali and U.S. colleagues, chased and reached the carrot at Matlab through the support of Langmuir and Mosley. Their study confirmed that some cholera patients could be rehydrated with oral rehydration therapy alone and that field staff could be trained to administer the therapy with ease. ${ }^{161}$ Most significant was their proof that oral rehydration therapy was a practical treatment which could be used to treat large numbers of patients in primitive conditions where little intravenous therapy was available.

With the Matlab study complete, ORT had one scientifically supported use: treatment for adult cholera patients. A host of researchers at the laboratory and in Calcutta recognized, however, that the potential extended far beyond cholera in adults. Nalin, Cash, and their colleagues, made the next significant breakthrough: they showed that oral rehydration solution is "as effective in the non-cholera diarrhoeal patients as in cholera

\footnotetext{
157 John R. Seal, MD, personal letter to Robert A. Phillips, 11 October 1968, Washington, DC.

$15 \times$ Ibid.

159 This incident further discredits the history of ORT presented in Van Heyningen's and Seal's book. The preface is extremely telling and explains well why the nature of such controversies was not described. In van Heyningen's section of the preface he writes that he "is grateful, deeply grateful, to his present collaborator, J.R.S. [John R. Seal], who proposed the writing of this book in the first place, and without whose encyclopaedic and unfailing support not only would this book never have been written, but many of the main events recorded in it would not have happened." (Emphasis mine). These words highlight the dedication with which this book presents Seal in the most positive light. Nothing of a critical nature is mentioned, not even the potentially detrimental relationship between Seal and Phillips. Op. cit., note 6 above, preface.

${ }^{160}$ Nalin, interview, 14 February 1992, transcript p. 14.

${ }^{161}$ Richard A. Cash, David R. Nalin, Roger Rochat, L. Barth Reller, Zahedul A. Haque, and A. S. M. Mizanur Rahman, 'A clinical trial of oral therapy in a rural cholera-treătment center', Am. J. Trop. Med. Hyg., 1970,19 (4): 653-6. Rochat and Reller were the Epidemiological Intelligence Service officers commissioned by Langmuir.
} 


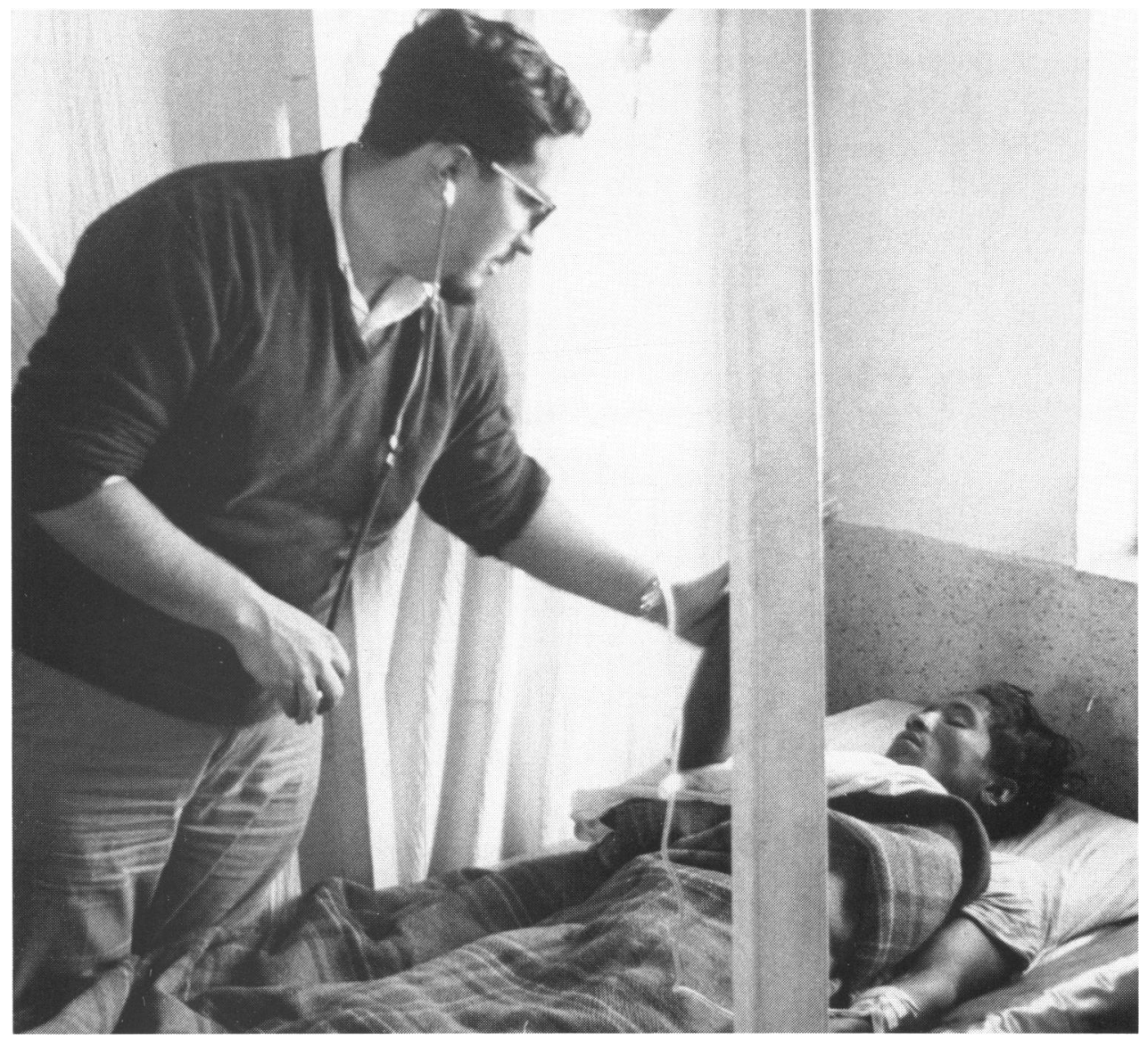

Plate I (a): This UPI photograph was taken at Matlab during the 1969 field trial and shows Nalin examining the pulse of a patient receiving IV rehydration to correct shock present on admission, prior to starting oral therapy (24 March 1969.) (Courtesy of the Bettmann Archive).

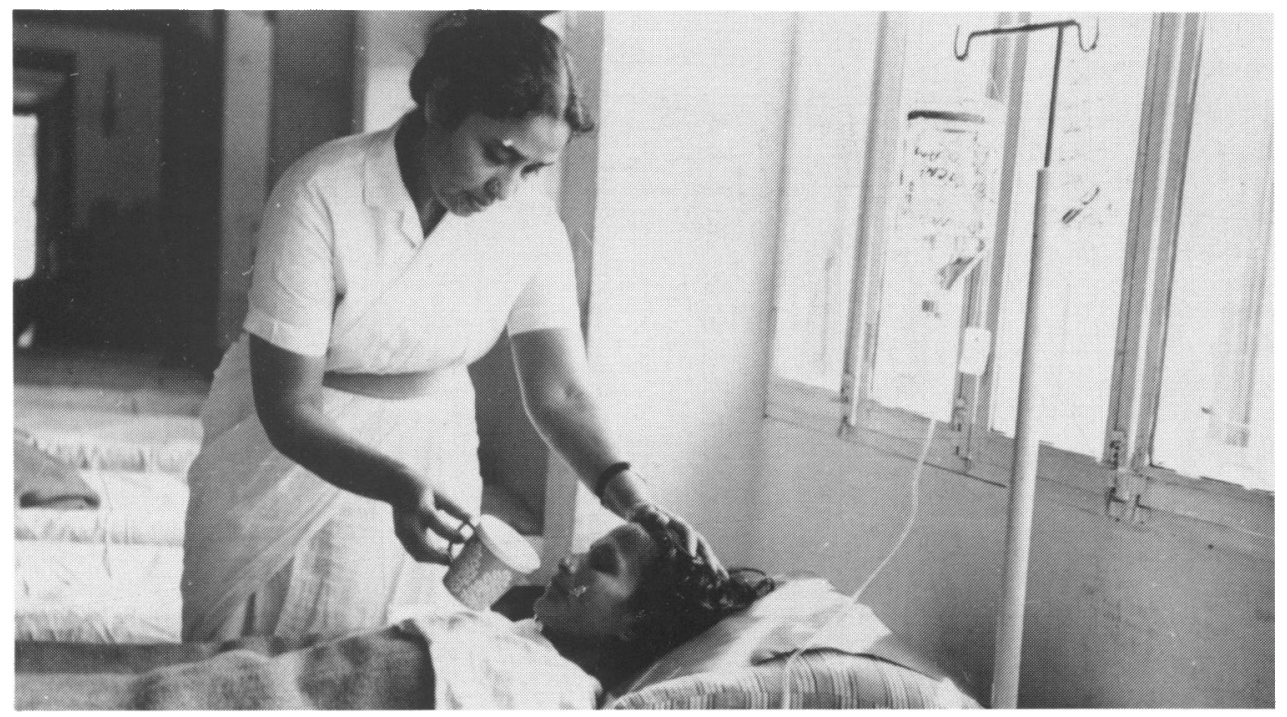

Plate l (b): This photograph, taken during the second protocol in Dacca, pictures the chief study nurse, Bashonti, starting oral therapy for a patient coming out of shock. Note that the IV, used for rehydration, is still connected.

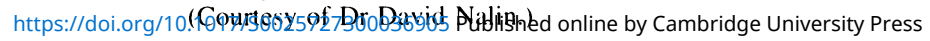



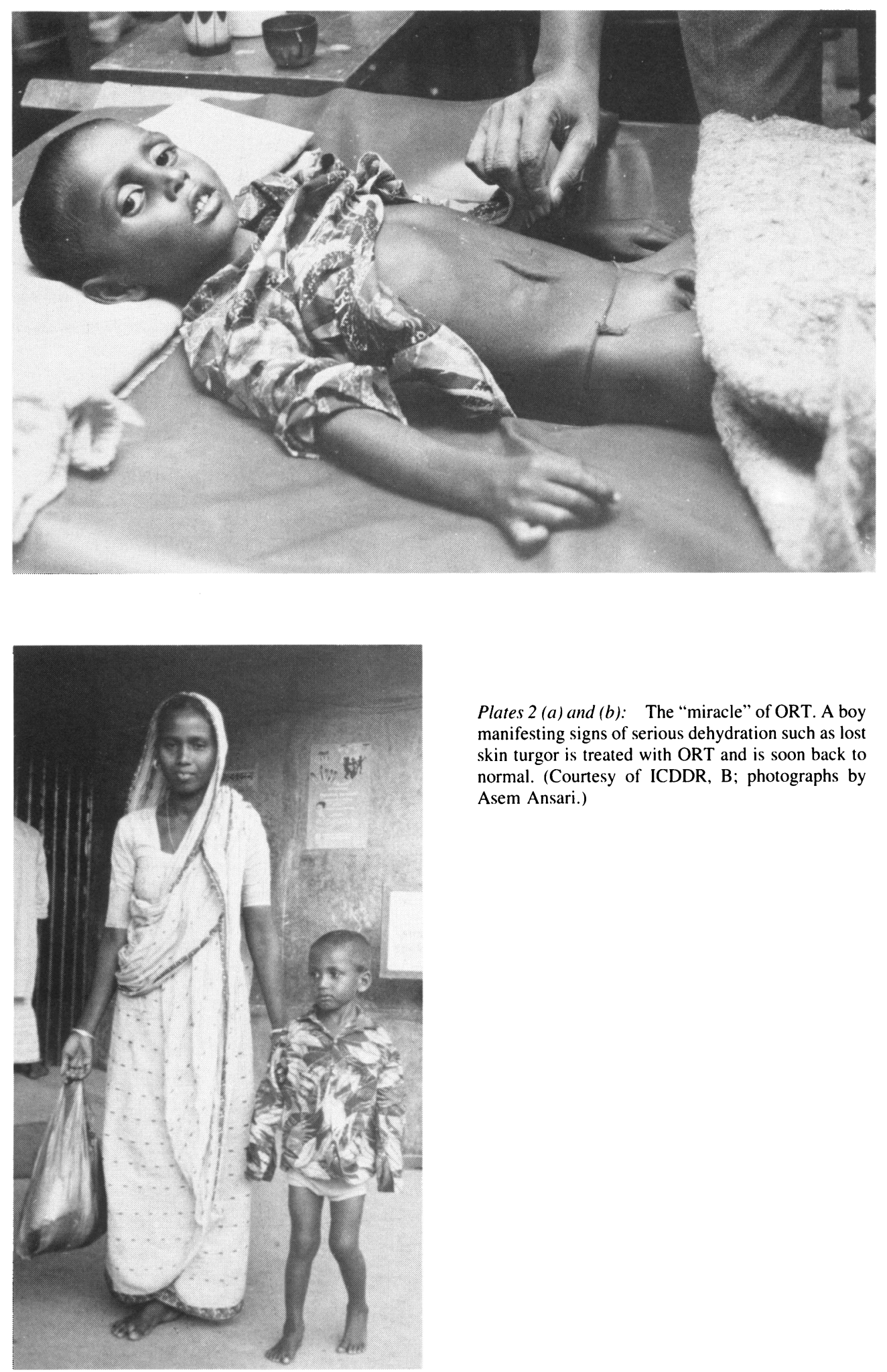

Plates $2(a)$ and ( $b$ ): The "miracle" of ORT. A boy manifesting signs of serious dehydration such as lost skin turgor is treated with ORT and is soon back to normal. (Courtesy of ICDDR, B; photographs by Asem Ansari.) 
Plates 3 (a) and (b): A girl suffering from dehydration is given ORT. Below, she is seen after the treatment. (Courtesy ICDDR, B; photographs by Asem Ansari.)
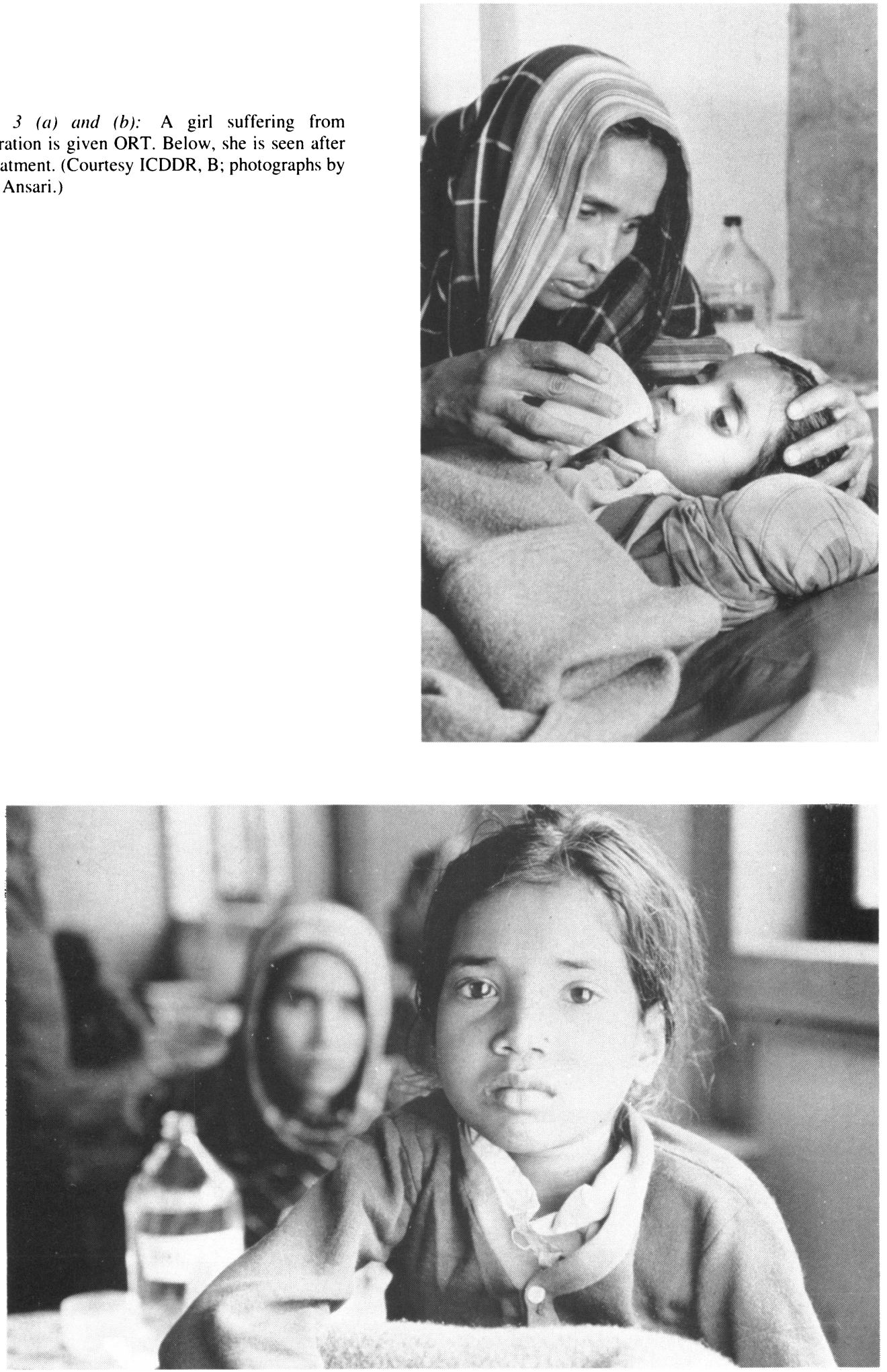


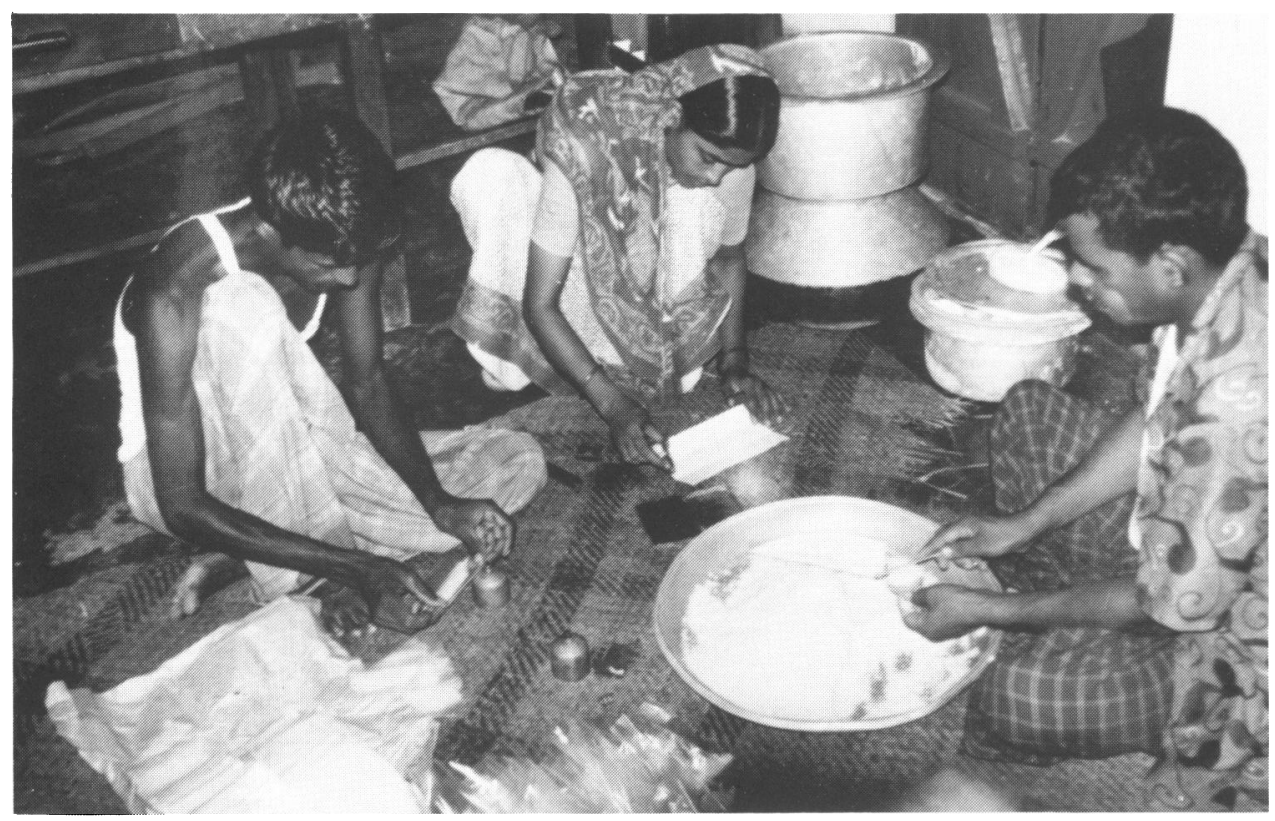

Plate $4(a)$ : Bengalis in Matlab mix the ingredients for oral rehydration solution and put them in small plastic packets for community distribution. (Photograph by the author.)

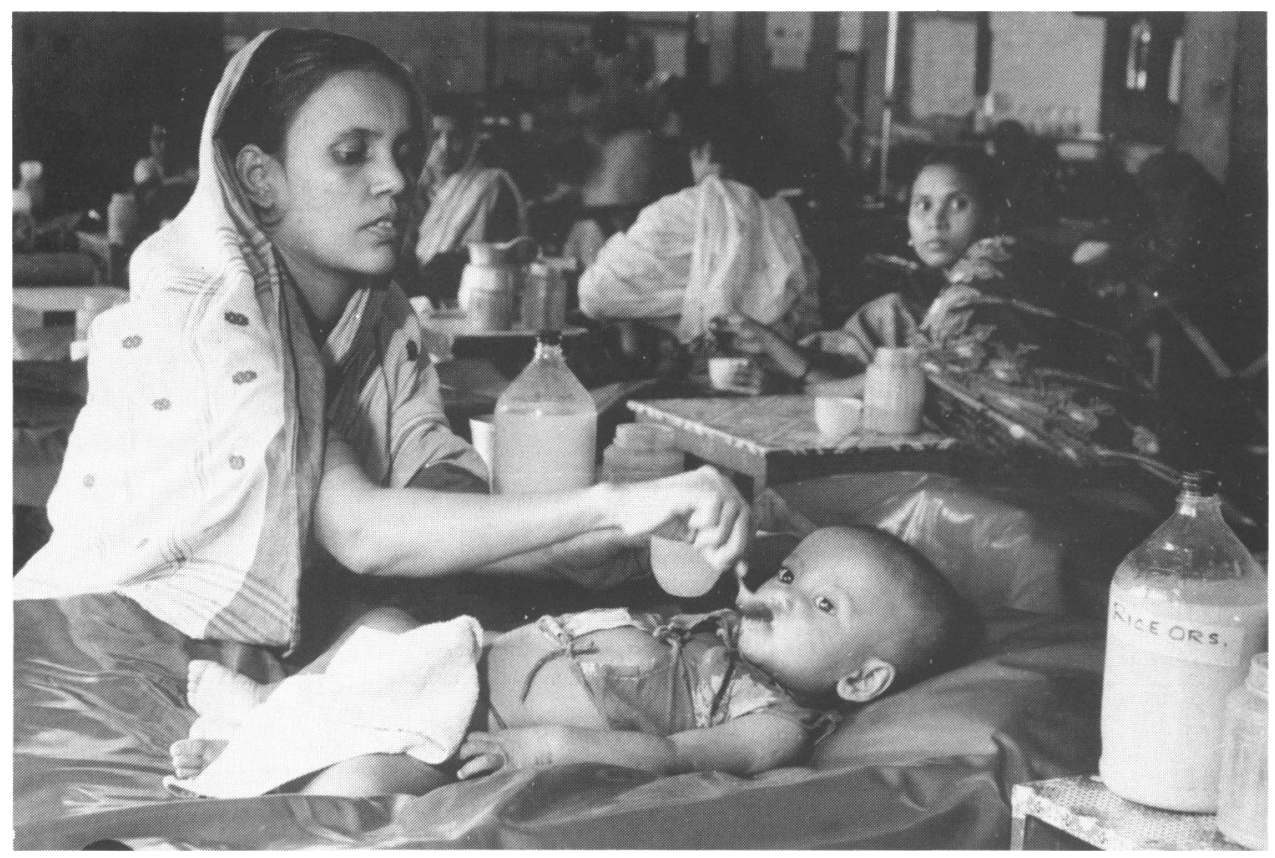

Plate 4 (b): The new rice-based oral rehydration solution being administered in Dacca. (Courtesy of ICDDR, B; photograph by Asem Ansari.) 
patients". ${ }^{62}$ In another study, Nalin and Cash and others showed that ORT alone may be used to treat moderate to severe dehydration. ${ }^{163}$ Additionally, they demonstrated the effective use of ORT in the treatment of children. ${ }^{164}$

\section{GAINING MOMENTUM}

Perhaps the greatest practical ORT success after Matlab was the Calcutta team's work demonstrating that ORT could be implemented even under disastrous circumstances. Dilip Mahalanabis led the challenging work in refugee camps during the Bangladesh War of Independence. ${ }^{165}$ Unlike the Matlab study, in which trained staff charted every patient, family members were responsible for the administration of the oral rehydration solution. ${ }^{166}$ Thus the refugee camp work not only proved that ORT could be used in emergency situations, but it also saved lives that otherwise would have been lost. Moreover, the work enabled ORT to "really hit the map ... [ [since] it probably took that kind of a demonstration in a crisis to really document what could be done". ${ }^{167}$ For those doctors such as Langmuir, who were involved with ORT on a political, behind-the-scenes level, Mahalanabis's work was crucial: "Cash and Nalin's work is tremendous, and I'm not denigrating that at all, but the Mahalanabis one turned me on". ${ }^{168}$ This comment shows how the Mahalanabis study differed from that at Matlab where, although the conditions were terrible, the study was smaller and it was entirely premeditated. Mahalanabis's work was quite simply a response to an emergency and therefore drew the attention of global health organizations such as the United Nations Children's Fund and the World Health Organization.

ORT began demonstrating success after success as physicians experimented with it in different cases of diarrhoea and among patients of all ages. In 1971 and 1972, soon after the work by Mahalanabis, Hirschhorn returned to ORT research, this time in Arizona. Under the influence of Bob Gordon, who six years earlier had sent Sachar to the Dacca laboratory, Hirschhorn worked with Apache children who were suffering from diarrhoea of various aetiologies (although never cholera).

He found that the treatment then being used for diarrhoea was "old-fashioned" since it called for intravenous fluids while starving the gut. ${ }^{169}$ Cash taught Hirschhorn how to use

\footnotetext{
162 David R. Nalin and Richard A. Cash, 'Oral or nasogastric maintenance therapy for diarrhoea of unknown aetiology resembling cholera', Trans. R. Soc. Trop. Med. Hyg., 1970, 64 (5): 769. It is important to recognize the distinction between oral rehydration therapy (ORT) and oral rehydration solution (ORS). ORS refers only to the electrolyte solution itself. ORT encompasses the use of ORS to replace fluid losses and maintain the patient, as well as the early commencement of nutritious feeding. Thus UNICEF and other organizations label their packets of salt, glucose, and citrate, "ORS", while championing ORT.

${ }^{16.3}$ Richard A. Cash, David R. Nalin, et cil., 'Rapid correction of acidosis and dehydration of cholera with oral electrolyte and glucose solution', Lancet, 1970, ii: 549-50.

16.+ D. R. Nalin, et al., 'Oral (or nasogastric) maintenance therapy for cholera patients in all age-groups', Bull. W.H.O., 1970, 43: 361. Mahalanabis asserts that the Calcutta group also demonstrated the efficacy of ORT in children between June 1969 and July 1970. Their publication, however, followed much later. D. Mahalanabis, R. B. Sack, et al., 'Use of an oral glucose electrolyte solution in the treatment of pediatric cholera-a controlled study', J. trop. Pediatr., 1974, 20: 82-7.

Ios Mahalanabis worked from March 1971 to the autumn at the southwest Indian/Bangladeshi border.

160 Norbert Hirschhorn, 'From bedside to worldwide: the progress of oral rehydration therapy', presentation at The Charles A. Dana Award For Pioneering Achievement In Health, 8 November 1990, pp. 5-6, 15-24. See also Dilip Mahalanabis, et al., 'Oral fluid therapy of cholera among Bangladeshi refugees', John Hopkins med. J., 1973, 132: 197-205.

${ }^{167}$ Mosley, interview, 25 February 1992, transcript p. 8.

${ }^{168}$ Langmuir, interview, 28 February 1992, transcript p. 2.

${ }^{169}$ Hirschhorn, interview, 10 January 1992, transcript p. 7.
} 


\section{Joshua Nalibow Ruxin}

ORT, and they achieved excellent results by implementing early feeding along with the therapy. Among their findings, they demonstrated that children down to the age of one month could be treated with oral therapy. Most importantly, their study indicated that dehydrated children would drink the solution to the point of hydration-they instinctively knew how much they needed. ${ }^{170}$ Within one year, Hirschhorn and others had confirmed their hunch that ad libitum oral therapy worked. ${ }^{171}$ Hirschhorn remarks that this discovery clearly showed the superiority of ORT over intravenous treatment, where the chance for error while administering the solution was much greater because intake and output had to be carefully recorded. ${ }^{172}$ ORT eliminated the necessity for that process since the patient would drink the proper amount.

\section{ORT ENTERS THE U.S.}

With his work in a Native American reservation, Hirschhorn brought ORT to the front locked doors of U.S. clinicians. Whereas the work in Dacca and Calcutta had involved cholera, an exotic affliction, Hirschhorn treated the kind of diarrhoea that was familiar to American physicians. Moreover, in Dacca ORT had been utilized under primitive conditions, but in the U.S. Hirschhorn used it in a technologically more advanced environment. An editorial comment following his ad libitum study stated that "a similar approach should be evaluated in modern urban settings under equally carefully controlled conditions". ${ }^{173}$ This illustrates the suspicion with which contemporary American medicine treated ORT, as well as the disbelief that a therapy so simple could out-perform high technology. One anecdote which Hirschhorn tells demonstrates this type of conservatism and arrogance, especially among paediatricians:

I had an anthropologist friend who adopted an Apache child from the reservation where we were working. He used to be the anthropologist on the reservation. And then he went to Arkansas to teach and the Apache child came down with severe diarrhoea and he called me up and he said desperately, "Look, my son's in the hospital and they're giving him all sorts of intravenous fluids. The diarrhoea's not stopping, he's losing weight, they're not feeding him. I know that you did this work in Arizona and it didn't look like that". And he said, "Would you call this professor of paediatrics and just collegiately talk to him?" So I called up the professor and told him that in our experience with Apache children this is what we found and here's the publication and so on. And he said to me, "Doctor, doctor, our children are not the same as your children". He was treating an Apache child from the same reservation. ${ }^{174}$

Clearly some doctors in the medical establishment viewed ORT as a solution for problems in the developing world, but not in the industrialized nations and, furthermore, they overlooked the substantial scientific evidence which supported its use. With the work of

\footnotetext{
${ }^{170}$ Norbert Hirschhorn, Richard A. Cash, William E. Woodward, and Gary H. Spivey, 'Oral fluid therapy of Apache children with acute infectious diarrhoea', Lancet, 1972, ii: 15-18, on p. 17.

171 Norbert Hirschhorn, Brian J. McCarthy, Bobbette Ranney, Mary Ann Hirschhorn, Susan T. Woodward, Ann Lacapa, Richard A. Cash, William E. Woodward, 'Ad libitum oral glucose-electrolyte therapy for acute diarrhea in Apache children', J. Pediatr., 1973, 83 (4): 562-71, on pp. 568-9.

172 Hirschhorn, interview, 10 January 1992, transcript p. 7.

17.3 William B. Weil, Jr. 'Editorial comment', J. Pediatr., 1973, 83 (4): 571.

${ }^{174}$ Hirschhorn, interview, 10 January 1992, transcript p. 10.
} 


\section{The history of oral rehydration therapy}

Crane, Sachar and other physiologists having been published, to deny the validity of ORT was to deny the findings of a decade of physiological progress.

In addition to ORT being supported by a relatively new physiological paradigm, other factors may have retarded its acceptance among physicians in the United States. In the early 1970s, the greatest use of ORT continued to be for cholera outbreaks in developing countries. UNICEF and the World Health Organization produced large numbers of oral rehydration solution packets and maintained these supplies at strategic locations around the world. ${ }^{175}$ The association of the therapy with disaster relief and the developing world may have contributed to the ongoing view in the States that ORT was for other children, other adults, and other diseases.

The poor coverage of ORT by the U.S. media did not encourage the public or the medical establishment to recognize swiftly its efficacy. In the New York Times, for instance, coverage of cholera epidemics throughout the world consistently overlooked ORT. In a 1971 article entitled 'Cholera now spreading to remote regions', the author wrote that "modern methods for delivery of fluids directly into the bloodstream has made it possible to save victims seemingly on the point of death". ${ }^{176}$ ORT was not even mentioned; an omission which is all the more conspicuous since the article refers to "remote regions" where intravenous therapy would have been difficult to implement. ${ }^{177}$

An abundance of articles conveys similar ignorance. Ironically, another in 1971 covered the issue of dehydration brought on by boiled milk, but failed to mention ORT. Milk becomes more concentrated when boiled and turns into a hyperconcentrated solution of non-absorbable substrates which draws water out of a baby's body through the gut. The central point of the article was the fact that many doctors still prescribed boiled milk for babies with diarrhoea, thereby only exacerbating the disorder and furthering dehydration. Contrary to expectations, the doctor interviewed did not suggest ORT as an alternative, rather, he prescribed, "fruit juices, clear beverages, Jello-water, cola or other nonchilled carbonated beverage[s]". ${ }^{178}$ While these could be more effective than the milk, they are not comparable to a glucose-sodium solution. Articles like these reflect the minimal impact that ORT had had on medicine and the media in the U.S.

\section{THE INTERNATIONALIZATION OF THE CHOLERA RESEARCH LABORATORY}

The type of neglect which ORT received in the U.S. media contrasts sharply with its rapid implementation elsewhere. Scientific support for the use of ORT worldwide had

\footnotetext{
175 Ibid., p. 6.

176. 'Cholera now spreading to remote regions', New York Times, 26 September 1971, p. 77. See also 'Cholera clinic in Dacca periled by cutoff in funds', New York Times, 28 May 1972, p. 2. Lawrence K. Altman, 'Health agency, expecting cholera to spread, begins to train doctors in black Africa', New' York Times, 8 September 1970, p. 10. The New York Times first reported the discovery of "a salty drink" (ORS) for the treatment of cholera in 1970: Lawrence K. Altman, 'Simple cholera treatment, a salty drink, developed', 28 September 1970, p. 9. In this newspaper, the article remains unique for its exclusive discussion of the effectiveness of ORT. Through the 1970s writers for the New York Times either omitted ORT or mentioned it only in passing. In 1983, however, the editors advocated ORT along with other child survival techniques that UNICEF had recently publicized. See "All God's children', New York Times, 31 December 1983, p. 22.

177 Other popular periodicals such as Time and New sweek ignored ORT and published no more than six articles on the subject between 1960 and 1980.

17x Jane Brody, 'Boiled milk a peril for diarrheic baby'. New' York Times, 4 July 1971, p. 29.
} 
reached the press by 1971 , with the completion of the work by Mahalanabis and Hirschhorn. Within six years there was a tangible global plan for the promotion and utilization of ORT. It seems supremely ironic that just as ORT began its journey toward universal usage, the Cholera Research Laboratory where the therapy had first proved effective faced severe difficulties. By 1976, decreased international interest and the secession of East Pakistan (and the establishment of Bangladesh) had placed the Cholera Research Laboratory in a dire financial condition. At that time, Greenough, Mosley, and others set out to internationalize and expand the laboratory. ${ }^{179}$ Greenough states that the major difficulties which it faced grew out of the lack of "any political commitment or any support, other than for scientific projects, to implement any of the knowledge that had been gained up to that point". ${ }^{180}$ Despite the obstacles, ORT managed to achieve worldwide notoriety and acceptance in record time.

In 1979, the Cholera Research Laboratory was officially designated the International Centre for Diarrhoeal Disease Research, Bangladesh. No longer was cholera the primary target for rehydration research. The World Health Organization recognized that "In non-epidemic seasons... [cholera] accounts for less than $5 \%$ to $10 \%$ of all acute diarrhoeas in cholera endemic areas". ${ }^{181}$ The Advisory Group for the World Health Organization's diarrhoeal disease programme met in Geneva in May 1978 and studied a number of tactics which could be used in the fight against such diseases. For many of the vaccine and drug programmes there was insufficient information or justification for their implementation. However, the Group concluded that "oral rehydration therapy was a strategy that could be put into effect now with the available means and have an immediate and far-reaching impact". ${ }^{182}$ The Advisory Group created a global oral rehydration programme seven years after sufficient evidence for the efficacy of ORT had been published. ${ }^{183}$

\section{THE O IN ORT}

For a discussion about the development of ORT to have any significance an explicit examination of what is meant by oral rehydration therapy is required. For example, the misleading contention that Hirschhorn and Pierce's work in 1966 constituted oral therapy appears in a variety of forums, from conferences to medical journals. To suggest that they used an oral solution implies that although theirs was given intragastrically (and multi-luminally in the case of Hirschhorn), it was virtually a practical therapy. The scientific record contests this conclusion. Although their work made use of a solution similar in composition to Nalin's, they were carrying out metabolic studies. The instrumentation which they used was too bulky to be practical. Hirschhorn himself maintains that after his work in Dacca and his departure from the Cholera Research

\footnotetext{
${ }^{179}$ Greenough, interview, 10 January 1992, transcript pp. 5-6.

180) Ibid.

$1 \times 1$ 'Control of diarrhoeal diseases: WHO's programme takes shape', op. cit., note 7 above, p. 369.

$1 \times 2$ Ibid., p. 372.

$1 \times 3$ The story of ORT after 1968 remains mostly unexplored, perhaps because many of the people most interested in it (and able to write about it) are engaged in a fierce battle for its acceptance. I attempted to piece together some of the politicking which succeeded the studies of Mahalanabis and Hirschhorn in the early 1970s but found that it deserves an essay of its own.
} 


\section{The history of oral rehydration therapy}

Laboratory, he "was not optimistic that ORT was feasible as a routine treatment. That task was left to David Nalin and Richard Cash". ${ }^{184}$ Hirschhorn's comment evokes the image of a runner handing over the baton to another and implies that his work smoothly progressed to Nalin's and Cash's breakthrough. This view of the development of ORT - that it was a scientific progression-provides two frameworks for interpreting the discovery. The first examines it as the culmination of decades of research, while the second suggests that ORT may have been "discovered" soon after early glucose-sodium absorption research.

\section{THE ROAD TO ORT}

If the development of ORT were a simple progression, the treatment might have culminated from work begun as early as 1832 when Thomas Latta used a saline solution intravenously to treat cholera. ${ }^{185}$ Despite some encouraging results, he did not further his research. His work may, however, be considered as the beginning of the intravenous therapy that Leonard Rogers advanced and Phillips virtually perfected in the late $1950 \mathrm{~s} .{ }^{186}$ Nevertheless, reconstructing the discovery of ORT over a century stretches the limits of definitively identifying a scientific progression.

While the 1830s may seem too distant to establish linearity, the transport work completed in the 1950s seems to signify a point of departure, albeit a minor one, for findings that resulted in ORT in 1968. One could credibly argue than any one of the major physiological breakthroughs beginning with Darrow's denotes the start of the development of ORT. Although the discovery of ORT itself was not directly dependent on the physiological studies of the 1940s and 1950s, these, especially glucose-sodium co-transport theory, provided essential proof for the theoretical utility of ORT since, according to Hirschhorn, "empirical findings were probably not enough to solidify a therapy". ${ }^{187}$ In other words, even if someone had stumbled onto the correct mixture for oral therapy, it would not have been accepted without supportive physiological paradigms because so much evidence against oral therapy had accumulated.

Despite the appearance of a single progression in the development of ORT, in retrospect one can in fact differentiate two distinct lines of scientific work leading to the discovery. The first, the development of co-transport theory, began with Crane, Riklis, and Quastel in the 1950s, and peaked with Schultz and Curran in the mid-1960s. The second, the execution of numerous metabolic studies, began with the serendipitous observations of Phillips in the Philippines. Sachar's work evolved from Phillips' poisoned sodium pump, and Hirschhorn executed his experiment because of Sachar's work and Phillips' study. These two physiological developments were confirmed in Phillips' work since he demonstrated that the molecular connection between sodium and glucose worked in vivo.

The view of the scientific establishment on the discovery and development of ORT overlooks the practical work in Dacca and Calcutta and reserves its ultimate praise for the

\footnotetext{
${ }^{184}$ Hirschhorn, op. cit.. note 166 above, p. 18.

185 Norbert Hirschhorn, 'The treatment of acute diarrhea in children: an historical and physiological perspective', Am. J. Clin. Nutr., 1980, 33: 637-63, on pp. 637-8.

I'c See Raymond H. Watten and Robert A. Phillips, 'Potassium in the treatment of cholera', Lancet, 1960, ii: 999-1001.

${ }^{187}$ Hirschhorn, interview, 10 January 1992, transcript p. 1. Hirschhorn credits Nalin and Cash with having worked out the practical application for ORT. As to the question of who discovered ORT, Hirschhorn believes that it was "all a mosaic".
} 


\section{Joshua Nalibow Ruxin}

most theoretical studies. This attitude was well represented by the Lancet when the editors declared that "The discovery that sodium transport and glucose transport are coupled in the small intestine, so that glucose accelerates absorption of solute and water, was potentially the most important medical advance this century". ${ }^{188}$ This judgement implies that the findings of Crane, Schultz and Curran were the direct predecessors of ORT-a conclusion that ignores crucial metabolic studies and Nalin's brilliant leap to a practical regimen. ${ }^{189}$ The co-transport research was crucial primarily because the researchers who developed ORT could point to it for support. The statement in the Lancet reflects the temptation for historians and scientists to reduce scientific discoveries to a line of theoretical breakthroughs that appear to flow smoothly into practical applications. ORT is an example of the difficult path that may lead to a discovery-from Phillips' extraordinary observation to a simple solution any parent can administer to a sick child.

\section{THE POTENTIAL FOR ORT BEFORE 1968}

Given the extremely simple composition of ORT, one might expect that an examination of the medical literature would reveal previous, successful oral therapy experiments. Only one comes to light that not only was independent of many important physiological studies, but preceded them. In 1953, Hemendra Nath Chatterjee, an Indian doctor working on cholera in Calcutta, managed to rehydrate patients with "mild to moderately severe cholera ... without intravenous or parenteral transfusions" and published his findings in the Lancet. ${ }^{190}$ He treated 186 patients with an oral glucose-sodium electrolyte solution that closely resembled the one employed by Nalin fifteen years later, and there were no fatalities. However, Chatterjee's work failed to provide controls and net fluid balance sheets, scientific tools that might have fostered credibility; ${ }^{191}$ and his use of exotic Indian plants to halt vomiting and diarrhoea, as well as his administration of some rehydration therapy by enema may have struck the readership of the Lancet as being too foreign and unscientific. Whatever the case, his article failed to stimulate follow-up studies. It is generally agreed that racism or the lack of a "scientific" rationale prevented the widespread adoption of his work. ${ }^{192}$

While Chatterjee's study did not present or cite a supportive physiological paradigm and could therefore be branded as a fluke, one might question whether a doctor could have extrapolated an effective oral therapy from early glucose-sodium co-transport studies. The experience of Qais Al-Awqati, an Iraqi physician, implies that this was in fact possible.

In 1966 a cholera epidemic erupted in Baghdad where Al-Awqati was doing his medical residency. Although he lacked scientific training and was unaware of the research in Calcutta and Dacca, Al-Awqati had studied the physiological experiments of Crane and, decided to try an oral electrolyte solution based on them. During the six weeks of the

\footnotetext{
188 'Water with sugar and salt', editorial, Lancet, 1978, ii: 300.

${ }^{189}$ Interestingly, Schultz contends that the discovery "was largely a matter of an idea whose time had come". By 1968 , Schultz would argue, there was such an accumulation of scientific evidence for a practical oral therapy that the development of a regimen was destined to occur. Schultz, interview, 24 February 1992, transcript p. 2.

${ }^{190}$ Hemendra Nath Chatterjee, 'Control of vomiting in cholera and oral replacement of fluid', Lancet, 1953, ii: 1063.

191 Cash, op. cit., note 39 above, p. 10.

${ }^{192}$ Schultz, interview, 24 February 1992, transcript p. 6. Nalin, interview, 14 February 1992, transcript p. 16. Field, interview, 19 February 1992, transcript p. 4.
} 


\section{The history of oral rehydration therapy}

epidemic, he successfully treated the majority of his 500 patients with an imprecisely measured glucose-sodium solution. This allowed the doctors to reserve the intravenous treatment exclusively for patients in shock. The experience inspired Al-Awqati to continue work on the topic since "there is nothing more impressive than seeing somebody down to zero blood pressure, somebody at death's door, and they [have a little intravenous therapy and a lot of oral rehydration therapy] and can leave the hospital in a few days". ${ }^{193}$

The experiences of Al-Awqati in Iraq and Chatterjee in Calcutta highlight how difficult a discussion of the date and circumstances of the "discovery" of ORT can be. Both men successfully used an oral solution but today receive no credit for their efforts and observations. Likewise, there may have been many other people who did similar work but never published. Clearly, for ORT to be an integral component of a global health programme a few carefully monitored clinical trials based on an accepted physiological paradigm were needed. Thus Nalin and Cash were the first to demonstrate oral therapy as a practical therapeutic alternative to parenteral therapy in April 1968. However, their work did not occur in a vacuum; a myriad of other findings were essential for a supportive physiological paradigm.

Al-Awqati's experience demonstrates that physiological research could have provided an essential framework for developing an oral therapy. ${ }^{194}$ But in the 1950 s, the physiological paradigm under which Western physicians operated was that intravenous therapy was superior to all others. Thus, a researcher who read the study by Chatterjee might have thought that the concept was interesting but that Western medicine had surpassed any simplistic (and therefore inferior) solutions to cholera. Intravenous therapy appeared more scientific, there was an apparatus, and the physician could have precise control over the intake of a patient. Oral therapy appeared primitive and less controlled. Thus, Chatterjee may have failed to inspire additional researchers because they had a psychological block which impaired their ability to consider or replicate his results.

ORT might also have been developed long before 1968 but for the attitudes of the dominant medical establishment toward practical experimentation, which the Cholera Research Laboratory and the National Institutes for Health shared. Nalin believes that "the people at the lab ... got kudos for the extent to which [their] work was not practical. As soon as it became practical it was discarded like a soiled towel-it was too common, too hands-on ... so the prestige went to people who measured trans-intestinal fluxes or electrical currents". ${ }^{195}$ Phillips, who wanted nothing to do with practical applications, no doubt profoundly influenced Nalin's perspective. However, he was a talented researcher and a better rounded scientist than these incidents reveal. His methodology for experimentation was to test a brilliant idea on a very small scale; if the results were positive, he would then continue. This framework clashed with the desire of Nalin and

\footnotetext{
19.3 Qais Al-Awqati, interview, 19 February 1992, transcript p. 2. See also Qais S. Al-Awqati, Mehdi Mekkiya, and Mahmud Thamer, 'Establishment of a cholera treatment unit under epidemic conditions in a developing country`, Lancet, 1969, i: 252. This article was written only after Al-Awqati arrived in the United States and was encouraged by Dr Greenough. The editors of the Lancet rewrote the article and hardly mentioned that the doctors had used oral therapy, concentrating instead on the public health perspective of the story.

${ }^{194}$ Nalin discourages this notion and states that the paradigm that there is "a logical progression from basic science to applied science [is| a fiction lin this instancel". Nalin, interview, 14 February 1992, transcript p. 17.

195 Ibid., p. 15.
} 
Cash to conduct large scale practical experimentation. Nalin states accordingly that Phillips "was the essence of the creative scientist whereas he reported to Seal [and the NIH as] the essence of the Bethesda bureaucrat". ${ }^{196}$

Although Phillips, the symbol of conservative medical approach in Dacca, influenced Nalin and Cash, they were sufficiently free from the dogma of the medical establishment to design and execute their own work. Hirschhorn and Pierce believe that one trait shared by nearly all the oral rehydration investigators was that, ironically, they had no training or experience in paediatric medicine. ${ }^{197}$ They were working towards a therapy that would benefit children, but they had not been indoctrinated by the paediatric medical establishment which embraced intravenous therapy and opposed oral therapy.

ORT, even in the light of co-transport theory, had to break through conceptual barriers in order to gain acceptance. Most investigators could not imagine patients swallowing and holding down the amount of fluid required for an oral therapy regimen. Nalin and Cash shattered this mental block with the second protocol demonstrating that the contrary was true. Since this work convinced only themselves and their immediate peers, I believe that it is appropriate to refer to their experiment in Dacca formally as the "discovery" of oral therapy. Their initial work, however, did not account for the global implementation of ORT programmes. Without the crucial diffusion that Mahalanabis and others inspired, ORT would have remained a discovery of far less importance. ${ }^{198}$

The amount of time needed for the U.S. medical establishment to accept ORT dwarfs the seven years that passed before the major public health institutions of the world embarked on a global ORT programme. In 1992 a small group of researchers met in Atlanta, Georgia, under the auspices of the Centers for Disease Control (CDC) to discuss a plan to benefit American children by promoting the therapy. The CDC had called the meeting in order to make a public statement on the value of ORT in the U.S. ${ }^{199}$ Organizations have been formed in the States to promote its use in hospitals and homes. ${ }^{200}$ Their existence testifies to the conservatism of a medical establishment, an identical attitude to that which slowed the development of ORT in the first place. ${ }^{201}$ This need to promote oral rehydration demonstrates that a superior therapy, even when supported by an ironclad physiological paradigm, may not necessarily be employed.

The formidable and persistent ignorance of the Western medical establishment, which continues over twenty-five years after the discovery of ORT, is phenomenal. While its

\footnotetext{
196 Ibid., p. 16.

${ }^{197}$ Hirschhorn, interview, 10 January 1992, transcript p. 2, and Pierce, interview, 31 March 1992, transcript p. 3.

${ }^{198}$ For a substantive description of the terms innovation and discovery, see John V. Pickstone. 'Introduction', in John V. Pickstone (ed.), Medical innovations in historical perspective. New York, St Martin`s Press, 1992, pp. $1-16$.

${ }^{199}$ Roger I. Glass, personal letter to Dr David Nalin, 3 March 1992. This meeting and subsequent research led to a Morbidity and mortality weekly report devoted to ORT. See Christopher Duggan, Mathuram Santosham, and Roger I. Glass, 'The management of acute diarrhea in children: oral rehydration, maintenance, and nutritional therapy', MMWR, 16 October 1992, 41.

${ }_{2(K)}$ For example, The National ORT Project in Washington, DC.

201 Oral rehydration development continues today. In the late 1970s researchers developed a cereal-based oral rehydration therapy which rehydrates the victim and decreases the quantity of stool. Today, at the cholera research hospital where Cash and Nalin first tested an oral therapy, rice-based ORS is the solution of choice. Although cereal-based oral solution has been hailed by some as superior to the original, there is no decisive evidence to this effect.
} 
refusal to advocate ORT may be due in part to the notion that ORT is only necessary for people in the developing world, its actions appear to be driven also by financial considerations. Most hospitals do not train physicians in the use of ORT since they have no financial reason to do so. ${ }^{202}$ The use of intravenous therapy, which often involves keeping a dehydrated child overnight, assures maximum insurance reimbursement. Sending children home with ORT would destroy these profits. Furthermore, recent studies show that diarrhoeal illness among the elderly may incur even greater health care costs that could also be reduced by the use of ORT. ${ }^{203}$ At a time of heated discussion about cost-containment in health care, it seems all the more ironic and egregious that a superior, cheap, and proven therapy continues to be superseded by a far more expensive one. Estimates based on the cost of hospitalizations and physician visits suggest that ORT could save billions of dollars annually. ${ }^{204}$ The dominant attitude toward ORT in the U.S. demonstrates that the medical powers that be need a new operational paradigm, one that grants credit to those who develop practical therapies as well as to those who use them. ${ }^{205}$

In contrast to the U.S., the developing world uses Oral Rehydration Therapy extensively. In addition to saving millions of lives there, its use should draw more attention to the poor water supplies and unsanitary living conditions that create such an immense need for the therapy. ORT is not a solution to the global epidemic of diarrhoea: it is only a treatment that prevents diarrhoeal deaths. ORT can buy time for nations and international development organizations to marshal their resources for clean water, sanitation, and other projects that constitute long-term solutions to diarrhoeal disease.

\footnotetext{
202 Greenough, personal communication, April 1994.

20.3 Of the 28,538 diarrhoeal deaths in the U.S. between 1979 and 1987,51 per cent occurred in adults over the age of 74. Richard G. Bennett and William B. Greenough III, 'Approach to acute diarrhea in the elderly', Gastroenterology Clinics of North America, 1993, 22 (3): 517-33, on pp. 517, 530, and William B. Greenough III, personal communication, April 1994.

${ }^{204}$ Recent studies indicate that 16.5 million children in the U.S. under the age of five have between 21 and 37 million episodes of diarrhoea annually. Roughly 3 million of these episodes lead to a visit with a physician and 220,000 are hospitalized. Eighty per cent of these hospitalizations could likely be avoided by ORT use. Approximately 400 children die annually from diarrhoeal illness in the U.S. See Roger I. Glass, et al., 'Estimates of morbidity and mortality rates for diarrheal diseases in American children', J. Pediatr., 1991, 118 (4): 27-33, on pp. 27, 32, and Roger I. Glass, personal communication, April 1994. Also David Nalin, personal communication, April 1994 and Greenough, personal communication, April 1994.

205 The CDC, among other organizations, has already accomplished relevant work. In its $M M W R$ devoted to ORT, the authors encouragingly concluded that "When the principles of [oral and nutritional] therapy that are outlined [in this publication] are accepted by all levels of the U.S. medical community, and when education of parents includes instructions about how to begin ORT at home, then unnecessary hospitalizations and deaths can be prevented". Duggan, et al., op. cit., note 199 above, p. 16.
} 